Segmentação e exploração de campos vetoriais usando projeção multidimensional 


\title{
Segmentação e exploração de campos vetoriais usando projeção multidimensional
}

\author{
Danilo Andrade Motta
}

Orientadora: Profa. Dra. Maria Luísa Bambozzi de Oliveira

Dissertação apresentada ao Instituto de Ciências Matemáticas e de Computação - ICMC-USP, como parte dos requisitos para obtenção do título de Mestre em Ciências - Ciências de Computação e Matemática Computacional . VERSÃO REVISADA 
Ficha catalográfica elaborada pela Biblioteca Prof. Achille Bassi e Seção Técnica de Informática, ICMC/USP, com os dados fornecidos pelo(a) autor(a)

\begin{tabular}{|c|c|}
\hline \multirow[t]{3}{*}{ M922s } & $\begin{array}{l}\text { Motta, Danilo Andrade } \\
\text { Segmentação e exploração de campos vetoriais } \\
\text { usando projeção multidimensional / Danilo Andrade } \\
\text { Motta; orientadora Maria Luísa Bambozi de Oliveira. } \\
\text {-- São Carlos, } 2013 \text {. } \\
\quad 59 \text { p. }\end{array}$ \\
\hline & $\begin{array}{l}\text { Dissertação (Mestrado - Programa de Pós-Graduação } \\
\text { em Ciências de Computação e Matemática } \\
\text { Computacional) -- Instituto de Ciências Matemáticas } \\
\text { e de Computação, Universidade de São Paulo, } 2013 .\end{array}$ \\
\hline & $\begin{array}{l}\text { 1. Visualização científica. } 2 \text {. Campos Vetoriais. } \\
\text { 3. Segmentação. 4. Projeção Multidimensional. I. de } \\
\text { Oliveira, Maria Luísa Bambozzi, orient. II. Título. }\end{array}$ \\
\hline
\end{tabular}





\section{Dedicatória}

Dedicado aos meus pais que me trouxeram até aqui $e$ à Carina que me mantêm em frente. 



\section{Agradecimentos}

À Prof ${ }^{a}$. Maria Luísa Bambozzi de Oliveira, pela orientação, apoio e atenção, sem o qual essa pesquisa não teria sido realizada.

Aos Profs. Afonso Paiva Neto, Luis Gustavo Nonato e Paulo Pagliosa, pela paciência e colaboração, que me mostraram o que um pesquisador precisa almejar.

Aos colegas do Grupo de Processamento Visual e Geométrico (GPVG), pelas sugestões e companheirismo.

Aos meus pais Clovis e Maria, pelo exemplo de coragem e dedicação, ao meu irmão Rafael, que nunca para de me surpreender, e seu primogênito, já querido, a caminho.

À Carina, minha motivação e alegria a cada passo do caminho.

Ao Instituto de Ciências Matemáticas e de Computação (ICMC) pela oportunidade de me aperfeiçoar profissionalmente.

À Coordenação de Aperfeiçoamento de Pessoal de Nível Superior (CAPES), pelo apoio financeiro concedido que viabilizou a realização deste período de estudo e pesquisa, processo DS-7486558/M. 



\section{Resumo}

Neste trabalho propomos uma nova maneira de visualizar campos vetoriais, dados de considerável importância em vários ramos da ciência. Fizemos uma revisão bibliográfica sobre segmentação de campos vetoriais e desenvolvemos nosso próprio método. Neste método são extraídas informações do campo e, de distribuições de frequências dos dados coletados são formados vetores multidimensionais. Esses vetores são projetados em duas dimensões e os agrupamentos destes pontos são utilizados para formar a segmentação do campo original. Os profissionais que fazem uso de ferramentas de visualização científica possuem, em geral, informações relevantes sobre o domínio do campo vetorial, mas essa informação é raramente aproveitada nas técnicas de segmentação. A técnica desenvolvida permite que o usuário interaja com os resultados, de maneira intuitiva, corrigindo e explorando a segmentação usando seu próprio conhecimento. Como contribuições desta pesquisa podemos citar o mecanismo de interação com o usuário para o auxílio da segmentação e uma nova maneira para representar os dados colhidos de campos vetoriais em dimensão alta. 



\section{Abstract}

In this research we introduce a novel method for visualizing vector fields, data of considerable importance in several branches of science. We did a literature review targeting vector fields and developed our own method. In this method information is extracted from the field and, from frequency distributions of the collected data multidimensional vectors are created. These vectors are projected in two dimensions and clusters of these points are used to form a segmentation of the original field. The professionals that make use of scientific visualization tools have, in general, relevant information about the domain of the vector field, but this information is rarely exploited by segmentation techniques. The developed technique allows the user to interact with the results, intuitively, exploring and correcting the segmentation using his own knowledge. As contributions of this research include the mechanism of interaction with the user to aid the segmentation and a new method to represent the collected data from vector fields in high dimension. 



\section{Sumário}

Lista de Figuras . . . . . . . . . . . . . . . . . . xi

Lista de Tabelas . . . . . . . . . . . . . . . . . xiii

Lista de Algoritmos . . . . . . . . . . . . . . . xv

1 Introdução 1

1.1 Contexto e Motivação . . . . . . . . . . . . . . . . . 1

1.2 Segmentação de Campos Vetoriais . . . . . . . . . . . . 3

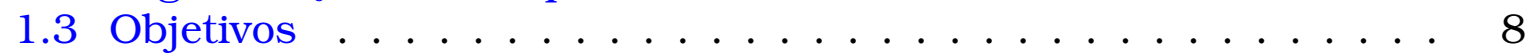

1.4 Contribuições . . . . . . . . . . . . . . . . . 9 9

1.5 Organização do trabalho . . . . . . . . . . . . . . 9

2 Segmentação e Exploração de Campos Vetoriais $\quad 11$

2.1 Considerações Iniciais . . . . . . . . . . . . . . . . 11

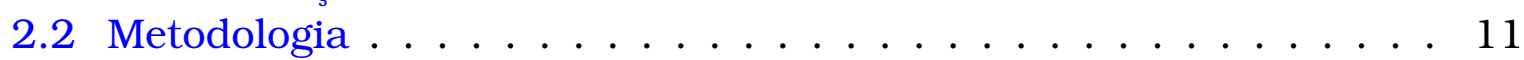

2.3 Extração de Características . . . . . . . . . . . . . . 12

2.3.1 Amostragem . . . . . . . . . . . . 13

2.3.2 Características ................ 20

2.3.3 Distribuição de Frequências . . . . . . . . . . . . . . . 27

2.4 Projeção multidimensional . . . . . . . . . . . . . . . 29

2.4.1 Local Affine Multidimensional Projection . . . . . . . . . . . . 30

2.5 Classificação e Visualização . . . . . . . . . . . . . . 31

2.5.1 Algoritmo de Agrupamento . . . . . . . . . . . . . 32

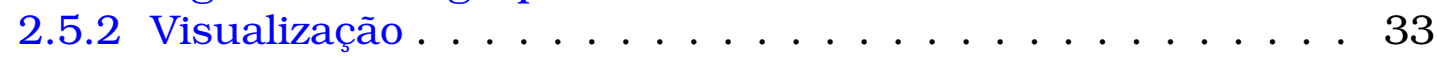

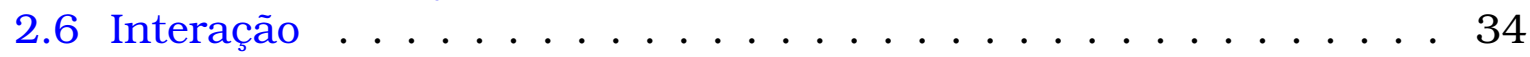

2.7 Considerações Finais . . . . . . . . . . . . . . 35

3 Resultados 37

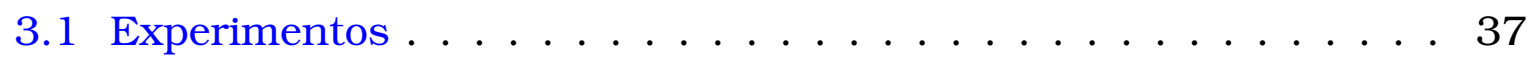

3.1.1 Dois vórtices . . . . . . . . . . . . . 37

$3.1 .2 U=\left(y, x^{2}\right) \ldots \ldots \ldots 38$

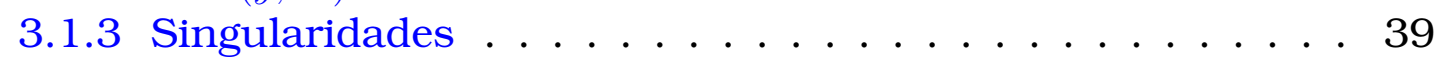

3.1.4 Correntes de ar . . . . . . . . . . . . . . . 40 40

3.1 .5 Von Kármán . . . . . . . . . . . . . . . . . . . . 40

$3.1 .6 \mathrm{PIV} \ldots \ldots \ldots 4 . \ldots \ldots 4 \ldots \ldots \ldots$

3.1.7 Interação com usuário: pontos de controle . . . . . . . . . 41 
3.1.8 Interação com usuário: número de agrupamentos . . . . . 42

3.2 Comparações . . . . . . . . . . . . . . . . . . . . 43

3.3 Extensão para 3D . . . . . . . . . . . . . . . . . . . . 45

3.4 Análise de esforço computacional . . . . . . . . . . . . . . 45

3.5 Considerações Finais . . . . . . . . . . . . . . . 46

4 Conclusões $\quad 51$

$\begin{array}{ll}\text { Referências Bibliográficas } & 53\end{array}$ 


\section{Lista de Figuras}

1.1 MAHROUS 2004. . . . . . . . . . . . . . . . 4

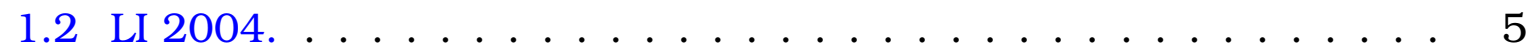

1.3 DANIELS $2010 \ldots \ldots \ldots$

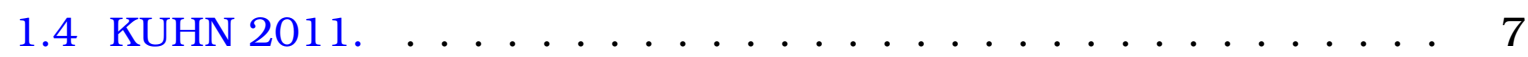

1.5 BHATIA $2011 \ldots \ldots \ldots \ldots$

1.6 RÖSSL 2012. . . . . . . . . . . . . . . . . 9

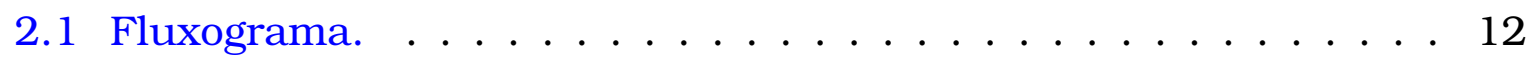

2.2 Streamline. . . . . . . . . . . . . . . . 14

2.3 Campo vetorial teste para os métodos de integração . . . . . . . 16

2.4 Resultado da integração usando método de Euler. . . . . . . . . . 17

2.5 Resultado da integração com método de Heun. . . . . . . . . . . . 18

2.6 Resultado da integração usando RK-4. . . . . . . . . . . . . . . 19

2.7 Ampliação nos resultados dos métodos de integração revisados. . 20

2.8 Erro médio. . . . . . . . . . . . . . . . 21

2.9 Erro máximo. . . . . . . . . . . . . . . 22

2.10Tempo de processamento . . . . . . . . . . . . 23

2.11 Campo vetorial inicial e campos escalares característicos. . . . . 24

2.12 Exemplos do conceito de magnitude de campos vetoriais. . . . . 25

2.13 Exemplos com operador divergente. . . . . . . . . . . . 25

2.14 Histogramas representando o vetor de características em dimensão

alta de três streamlines. . . . . . . . . . . . . . . . 29

2.15 Pipeline de visualização da segmentação 2D. . . . . . . . . . 33

2.16 Interação com o usuário: seleção. . . . . . . . . . . . . 35

3.1 Segmentação de campo vetorial artificial: dois vórtices. . . . . . . 38

3.2 Segmentação de campo vetorial artificial: $U=\left(y, x^{2}\right) \ldots$. . . . . . 38

3.3 Segmentação de campo vetorial: singularidades. . . . . . . . . . . 39

3.4 Segmentação de campo vetorial: ventos norte americanos. . . . . 40

3.5 Segmentação de um campo vetorial com estrada de Von Kármán. 41

3.6 Resultado da segmentação de dados PIV. . . . . . . . . . . . . . . 42

3.7 Resultado aprimorado pela interação com os pontos de controle. . 42

3.8 Interação com usuário: variação do número de agrupamentos. . . 43

3.9 Comparação com método baseado em espaço de dimensão alta. 44 
3.10 Comparação com método topológico. . . . . . . . . . . . . . . 44

3.11 Segmentação de campo vetorial 3D: corte do campo . . . . . . 48

3.12 Segmentação de campo vetorial 3D: campo completo . . . . . . . . 49 


\section{Lista de Tabelas}

3.1 Tempos computacionais (em segundos). . . . . . . . . . . 47 



\section{Lista de Algoritmos}

1 Erro aproximado. . . . . . . . . . . . . . . . . . 18

2 Representação teórica da obtenção dos vetores que representam as streamlines na dimensão alta. . . . . . . . . . . . . 28 



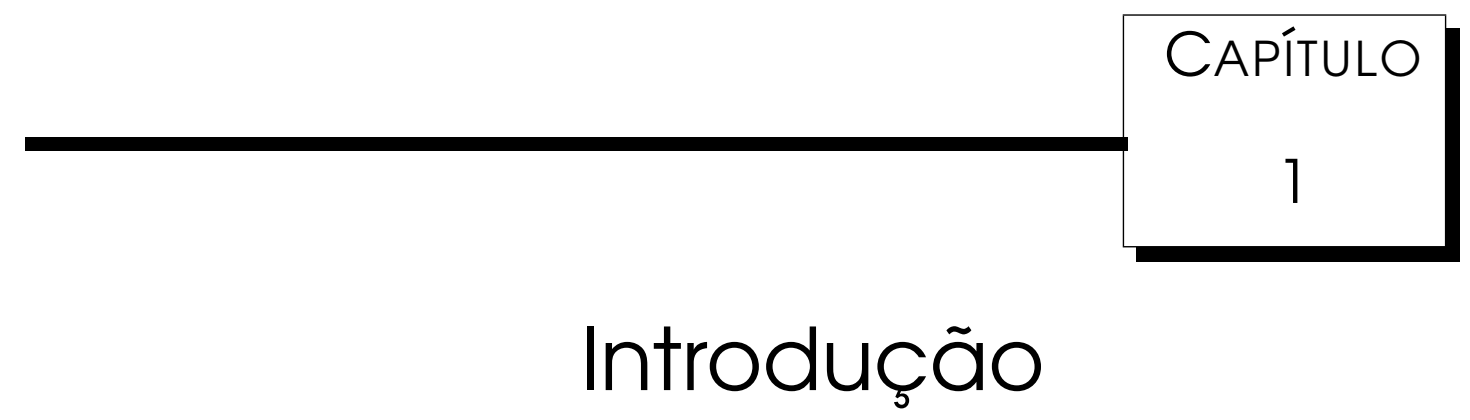

\subsection{Contexto e Motivação}

Visualização científica é, atualmente, uma área de pesquisa de grande importância devido ao volume de informação gerado a cada momento. Dados somente não podem ser qualificados como conhecimento. O conhecimento é criado a partir de observações e análise sobre os mesmos. Porém, a quantidade demasiada de informação torna inviável ao pesquisador apenas observar o montante de dados obtidos e tirar conclusões aceitáveis. Logo, precisamos de ferramentas que deem suporte à análise e assim possamos criar conhecimento. Nesse contexto, a visualização científica entra como auxílio ao pesquisador, simplificando e relacionando, de forma visual, informação anteriormente incompreensível.

Campos vetoriais são usados para representar resultados de simulações de fluidos [1, 2], experimentos controlados [3], estudos climáticos e oceanográficos [4], entre outros. Uma ferramenta para auxílio à análise desse tipo de dados é a proposta deste trabalho. Precisamos de ferramentas de visualização que permitam retirar o máximo possivel de informações relevantes desses resultados. Temos, então, grandes quantidades de dados que precisam ser filtrados de modo a revelar relações interessantes ao pesquisador.

O problema descrito é constantemente abordado em publicações da área de visualização, devido à sua importância. Podemos citar quatro frentes relevan- 
tes neste contexto: métodos baseados em topologia, em textura, em espaço de características e em primitivas geométricas [5].

Métodos baseados em extração de características topológicas foram introduzidos na área de visualização por Helman e Hesselink [6], e constantemente estudados, por exemplo, para o rastreamento de características [7], rastreamento de linhas principais de vórtices (vortex core lines) [8] e remoção de ruído em campos vetoriais [9]. Métodos baseados em topologia são efetivos e confiáveis. Entretanto, a implementação desses métodos é complicada, são computacionalmente custosos e, com algumas poucas exceções [9], não permitem a interação com o usuário durante o processo. Leitores podem consultar resumos publicados $[10,11]$ que relatam o estado da arte para as técnicas topológicas.

Os métodos baseados em textura utilizam mapeamento de padrões de cores ou tons sobre o campo vetorial para auxiliar a visualização de modo direto para o usuário. Abordagens utilizando textura geralmente têm baixo custo computacional, o que os tornam atrativos. Uma importante técnica baseada em textura, chamada Line Integral Convolution (ou LIC), foi publicada por Cabral et al. [12]. A técnica baseada em advecção de textura recebe como entrada um campo vetorial e uma imagem, o algoritmo extrai para cada pixel da imagem uma streamline do campo vetorial e, usando a informação local obtida da textura sobre a streamline, é gerada uma imagem de saída. A técnica sozinha não dá informação sobre a direção do campo vetorial; pós-processamento é indicado para dar noção de direção à imagem. LIC serviu de inspiração para outras pesquisas, incluindo a visualização LIC em volumes 3D, permitindo interação e animação de 3D-LIC [13, 14]. Técnicas baseadas em texturas dão intuição do comportamento do campo vetorial, mas não são utilizadas para segmentar o mesmo, e embora existam trabalhos em 3D, a oclusão é um problema evidente nestes métodos. Em nossos experimentos utilizaremos LIC para intuitivamente relacionar o resultado e o campo vetorial dado como entrada.

Métodos baseados em espaço de características são aqueles que levam o problema da visualização para uma dimensão alta para resolvê-lo. Para construir um espaço de características, esses métodos recolhem informações sobre os dados de entrada. Assim, para cada amostra é formado um vetor de atributos que representa a amostra em um espaço de dimensão alta. Da informação recolhida é gerada a visualização. O acúmulo de informação ao problema pode revelar propriedades antes não percebidas nos dados de entrada. Porém, em 
consequência, perde-se a noção espacial do relacionamento entre os dados, ou seja, não é intuitiva a percepção de distância. Logo é preciso um tratamento da informação extraída para formar uma representação visual inteligivel ao usuário. Utilizando espaços de dimensão alta podemos citar pesquisas em visualização de regiões com largas escalas de energia [15], exploração interativa de campos vetoriais 2D [16], exploração de streamlines em campos vetoriais 3D [17], no posicionamento de sementes de streamlines [18] e segmentação topológica de campos vetoriais 3D [19]. A pesquisa apresentada nesta dissertação será uma técnica que usa a dimensão alta para abordar o problema.

Métodos que se baseiam em objetos geométricos utilizam a visualização de stream lines (ou streamlines), stream surfaces, flow volumes, entre outros, para um melhor entendimento do comportamento do escoamento. Objetos geométricos são base para uma gama de métodos de visualização de fluidos: inspirados em transporte de tinta [20], utilizando curvatura e torção de curvas para encontrar e visualizar pontos críticos e extrair superfícies [21], extração de curvas que representam o núcleo de vórtices [22], filtragem para diminuir a oclusão em 3D [18, 23], além de ferramentas interativas baseadas em esboços [24], entre outros [25]. Estes métodos foram importantes para esta pesquisa, já que, usando objetos geométricos, iremos retirar uma importante limitação quanto à amostragem do problema, conforme veremos no capítulo 2 .

Dentre os métodos de visualização existem aqueles que segmentam o campo vetorial para auxiliar na compreensão do mesmo. A seguir revisaremos alguns destes trabalhos.

\subsection{Segmentação de Campos Vetoriais}

Diferentemente das técnicas vistas anteriormente, os métodos de segmentação propõem a visualização do campo vetorial assistida pela divisão do campo em regiões significativas. As mesmas são geralmente definidas de acordo com a topologia ou estruturas, como vórtices.

Uma técnica para segmentação de campos vetoriais $3 \mathrm{D}$, sobre malhas tetraedrais, foi proposta por Mahrous et al. [19], baseando-se na topologia do campo. Primeiramente, são detectados os pontos críticos. Em seguida são amostradas streamlines cujo início e fim jazem na fronteira ou em pontos 
críticos. Os tetraedros da fronteira ou que contêm um ponto crítico são classificados como tetraedros de término (terminating tetrahedra). Tetraedros de término são assinalados com um marcador $m$ que indica as características de seus triângulos componentes: triângulo de fluxo de entrada (inflow), triângulo de fluxo de saída (outflow) ou triângulo de fluxo tangente (tangential flow).

Um marcador $m$ é dado às streamlines que atingem um tetraedro de término marcado com $m$. Em seguida, para cada ponto de cada streamline é calculado o vértice da malha mais próximo. Ao vértice é incrementado um vetor de propriedades na posição $m$ indicando que foi atingido por uma streamline marcada com $m$. A partir daí, cria-se superfícies separadoras para demarcar as regiões de contato entre os diferentes vértices classificados de acordo com seus respectivos vetores de propriedades. O método descrito por Mahrous et al. [19] não permite interação e funciona somente em malhas volumétricas. Resultados do algoritmo de Mahrous podem ser vistos na figura $1.1 \mathrm{em}$ um campo vetorial de um tornado. Vemos à esquerda o inflow marcado em vermelho e outflow em verde. Na imagem do meio são adicionadas streamlines iluminadas. A imagem da direita mostra o resultado da segmentação separando streamlines que terminam em diferentes regiões de outflow.
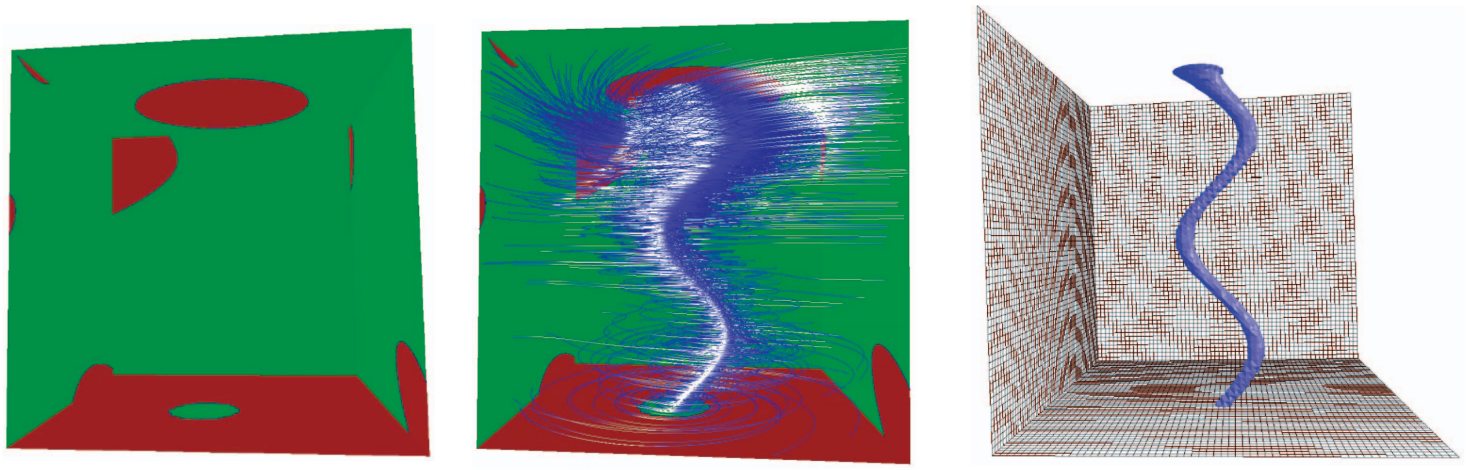

Figura 1.1: Resultados de Mahrous et al. (extraído de [19]).

Li et al. [26] propuseram um novo método automático para a segmentação de campos vetoriais bidimensionais. Do campo vetorial são extraídas duas funções usando o método da função de Green: uma escalar potencial (scalar potential function), cujo gradiente captura a parte livre de rotação (curl-free) do campo, e outra, uma função de corrente escalar (scalar stream function) cujo rotacional captura a parte livre de divergência do campo (divergent-free). É escolhido um dos campos escalares que melhor aproxima o campo vetorial e um corte normalizado segmenta esse campo escalar. O resultado do corte, sobreposto ao campo vetorial original, é a segmentação deste método. Finalmente, 
streamlines são posicionadas de forma a ficarem na borda entre as regiões segmentadas. Resultados produzidos por este método são apresentados na figura 1.2 onde: à esquerda vemos o campo vetorial original com os pontos de singularidade marcados (os sorvedouros $1,4,5$, e as fontes $2,3,6$ ) e com curvas vermelhas representando as streamlines; no meio o campo escalar; e à direita o resultado da segmentação.

É interessante observar que Li et al. [26] afirma que a segmentação ótima de campos vetoriais deve ser consistente com o conhecimento perceptivo, ou seja, que dados em torno de singularidades no campo devem ser agrupados juntos. O método não permite que o usuário interaja com os resultados nem insira informações previamente conhecidas e é apresentado somente em campos vetoriais $2 \mathrm{D}$.
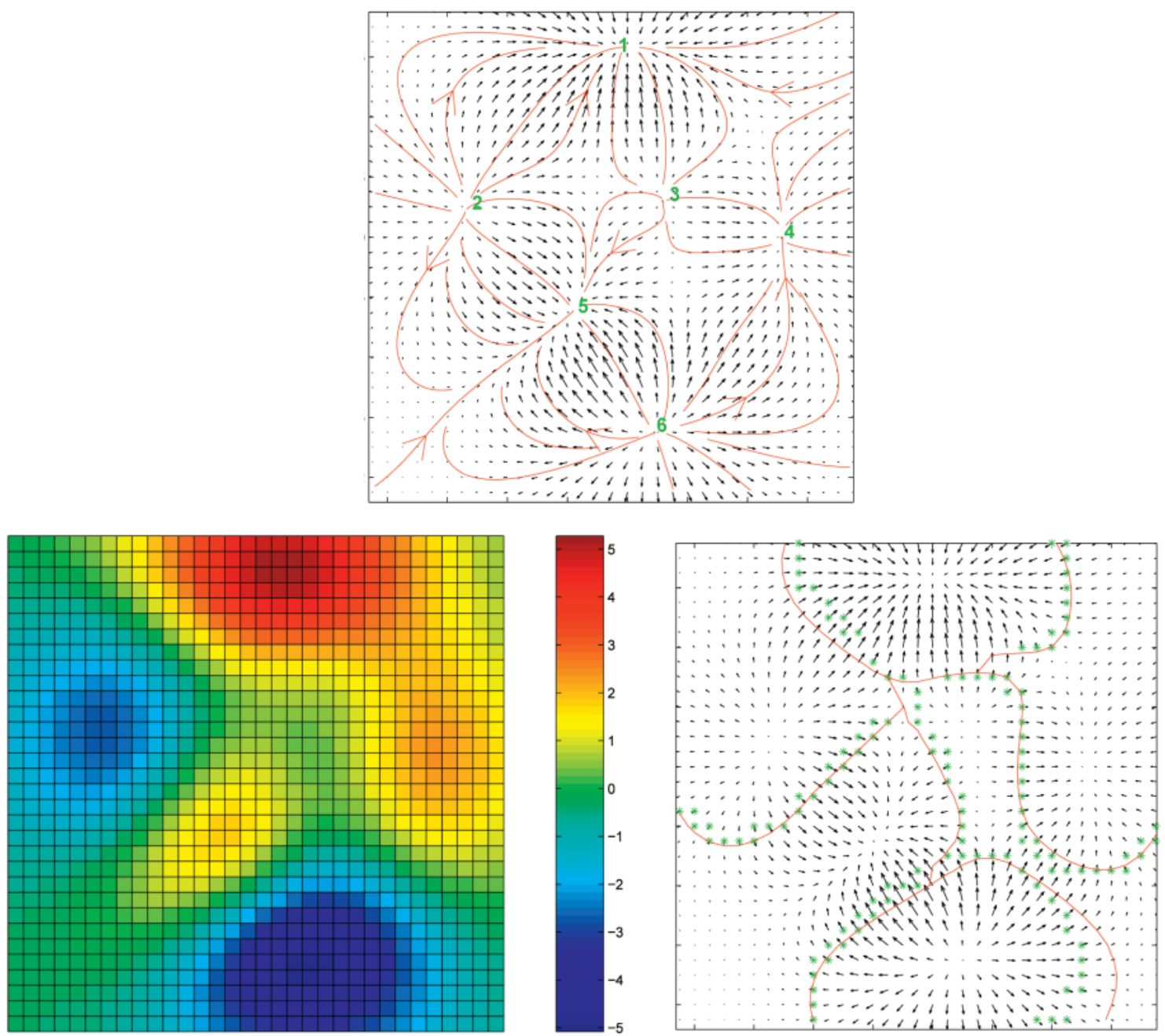

Figura 1.2: Segmentação realizada por Li et al. (extraído de [26]).

Daniels et al. [16] apresenta uma técnica baseada em projeção multidi- 
mensional (Least Square Projection [27]) para exploração interativa de campos vetoriais. Dado um ponto a ser classificado, são usadas informações do próprio ponto e da vizinhança do mesmo para levar o problema para a dimensão alta. Entre as características utilizadas têm-se $\lambda_{2}$ [28] e magnitude da velocidade, entre outras, semelhante às que estudaremos no capítulo 2 . São utilizados modelos pré-estabelecidos de propriedades que são interessantes à visualização do usuário (como os vetores de fontes e sumidouros) ou são selecionadas regiões de interesse como pontos de controle da projeção; assim, são separadas regiões relevantes do campo vetorial de acordo com a entrada do usuário. Em seguida, o usuário pinta regiões da projeção, gerando a segmentação colorizada no campo vetorial.

Resultados dessa proposta são mostrados na figura 1.3, onde a interação do usuário revela novas características sobre o campo vetorial. O trabalho apresenta uma maneira intuitiva para interação, porém é limitada a campos vetoriais $2 \mathrm{D}$ e não resulta em uma segmentação bem definida, onde se delimita claramente a interface entre os segmentos.
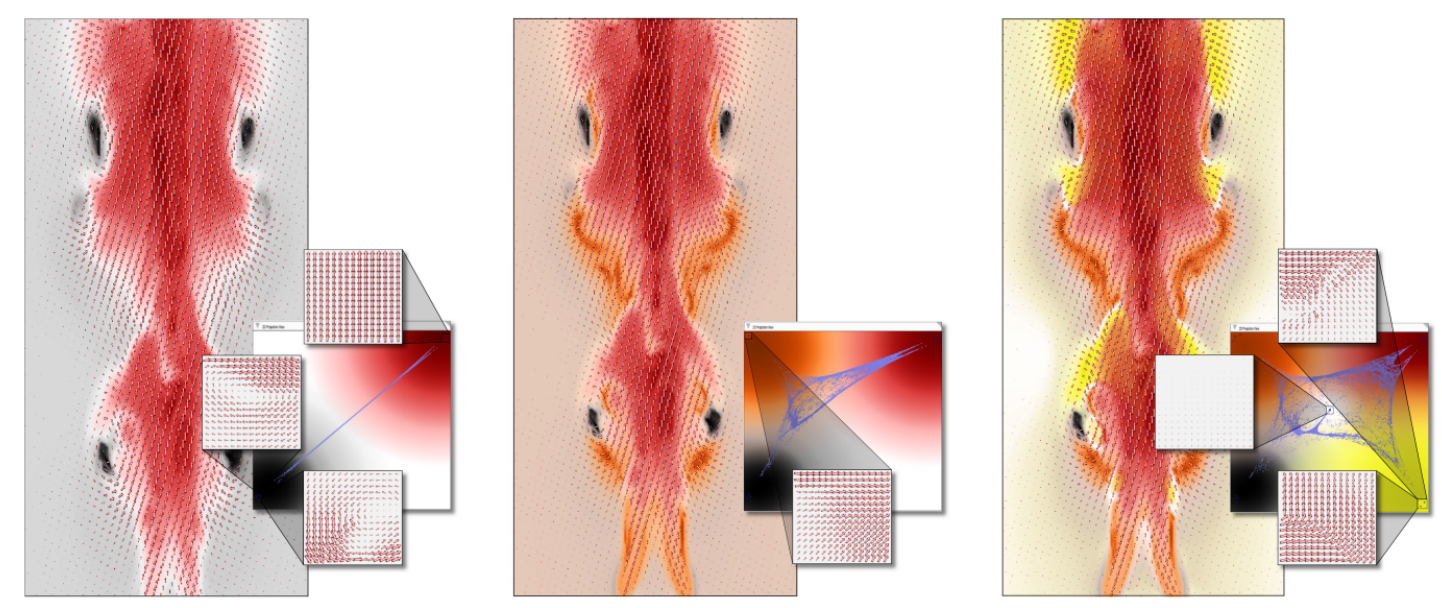

Figura 1.3: Segmentações geradas por Daniels et al. (extraído de [16]).

Em 2011, Kuhn et al. [29] agruparam e visualizaram as regiões de curvatura semelhante de campos vetoriais. Usando a integral da curvatura de subintervalos de tamanho $n$ de streamlines amostradas, é calculada a energia de dobramento (bending energy) do campo. Em seguida, cria-se um campo característico definido pelo valor da energia de dobramento onde ocorre a primeira mudança do comportamento do fluxo, dado pelo extremo da primeira derivada da energia de dobramento. O tamanho $n$ do subintervalo das curvas a ser considerado no cálculo é deixado a critério do usuário. Um algoritmo 
de agrupamento sobre o campo característico define os grupos que são representados por malhas suavizadas. O método é representado em $2 \mathrm{D}$ e $3 \mathrm{D}$ conforme visto na figura 1.4: a) LIC do campo vetorial original seguido por três segmentações com parâmetros variados e os dois campos característicos criados; b) dados originais seguidos por duas segmentações, onde laranja representa escoamento turbulento, azul, escoamento com vorticidade e verde, laminar. Este método não permite a interação do usuário ou o uso do seu conhecimento no processo, além da escolha de parâmetros.
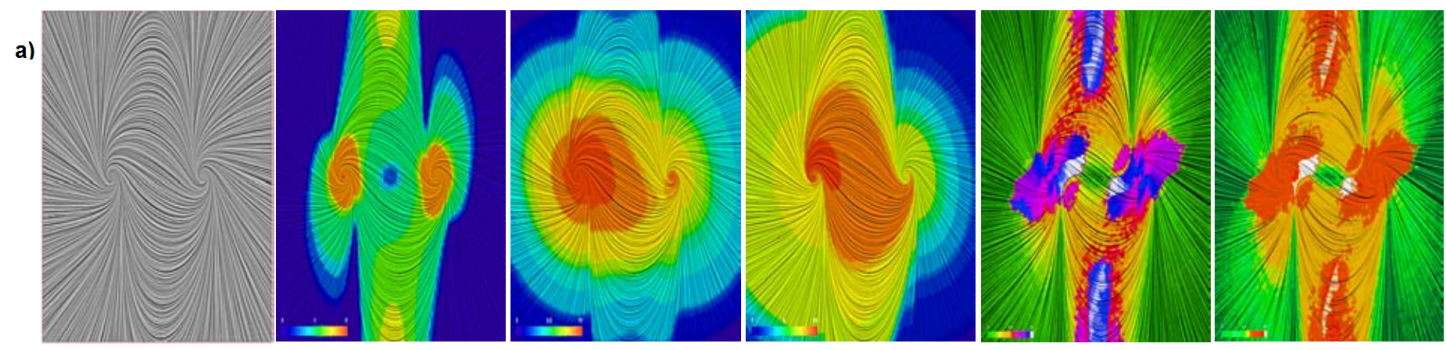

b)
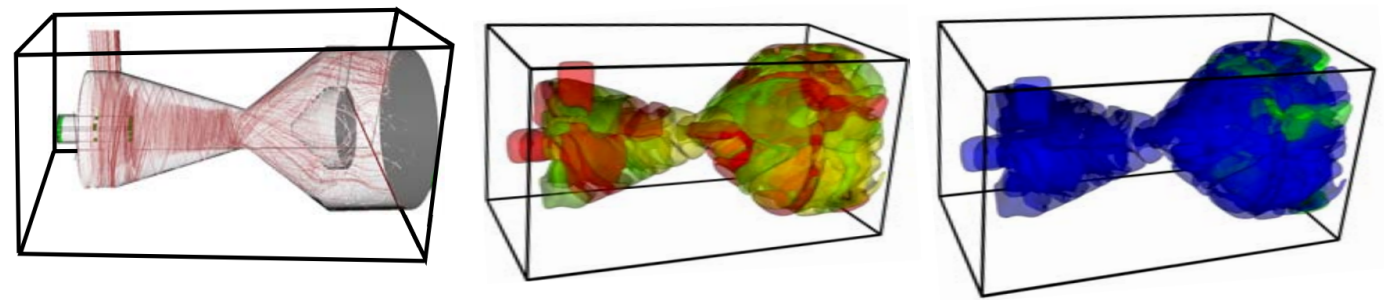

Figura 1.4: Segmentações realizadas por Kuhn et al. (extraído de [29]).

Em 2011, Bathia et al. [30, 31] apresentaram Edge Maps, uma nova representação para campos vetoriais. Essa técnica proporciona integração com erros limitados e garantia de informações consistentes. Por representar o campo vetorial usando uma triangulação do mesmo, o problema a ser tratado é subdividido entre as possiveis ocorrências dentro de cada triângulo. Uma segmentação topológica é demonstrada usando streamwaves (possiveis caminhos que uma partícula sem massa poderia tomar levando em conta o erro espacial) que são classificadas como parte do mesmo grupo, quando começam e terminam nas mesmas arestas e singularidades.

Resultados do método em um campo vetorial sintético sobre uma malha podem ser vistos na figura 1.5. Linhas vermelhas identificam que regiões se sobrepõem quando erro é introduzido. Como a maioria dos métodos topológicos, esse método depende da identificação de pontos críticos, não permite interatividade e possui uma implementação complexa. 

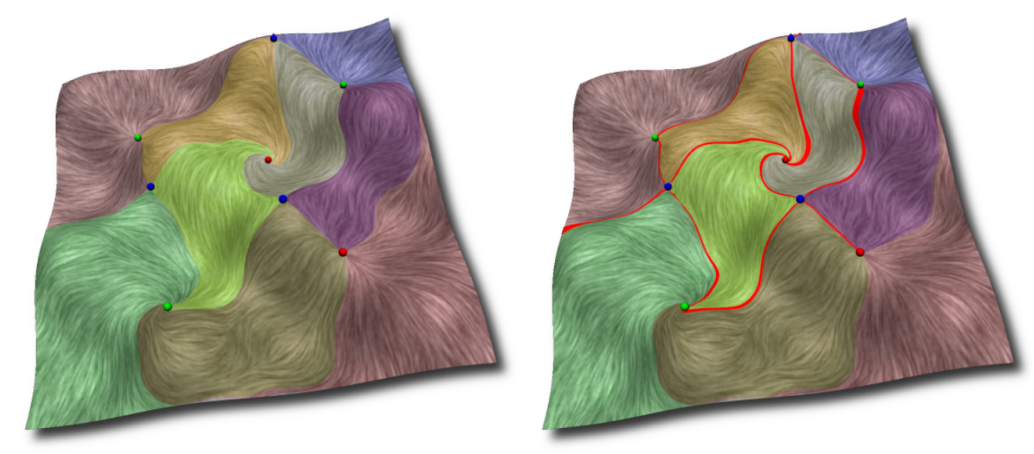

Figura 1.5: Segmentação topológica realizada por Bhatia et al. (extraído de [30]).

Rössl e Theisel [17] em 2012 publicaram uma nova técnica para visualizar streamlines em campos vetoriais. É gerado um mapeamento das mesmas em pontos do $\mathbb{R}^{3}$. Usando a distância de Hausdorff [32] de cada par de pontos e aplicando-se Multidimensional Scaling [33], a técnica garante que pontos em $\mathbb{R}^{3}$ serão próximos quando as streamlines estiverem próximas no espaço de Hausdorff. É realizado o agrupamento dos pontos no $\mathbb{R}^{3}$ e as streamlines são pintadas de acordo com seus grupos. O método permite interação com os resultados onde o usuário pode selecionar pontos ou streamlines para encontrar seu correspondente ou grupo ao qual pertence. Além disso, pode-se selecionar uma região para explorar. Resultados desse método são demonstrados na figura 1.6. À esquerda é mostrada a segmentação de um campo vetorial artificial e à direita para dados de uma simulação de aneurisma. Ao lado de cada uma vemos projeções no espaço visual 3D.

O método de Rössl e Theisel [17] calcula uma matriz $N^{2}$, onde $N$ é o número de streamlines; logo, os tempos de computação serão altos. O conhecimento do usuário não é utilizado no processo de segmentação apesar da interatividade.

Após revisar a literatura sobre segmentação, salientamos que nenhuma das técnicas observadas cobrem todos os objetivos que serão traçados neste trabalho, conforme vistos a seguir.

\subsection{Objetivos}

Os principais objetivos deste trabalho são:

- A implementação de uma nova técnica para segmentação de campos vetoriais;

- O agrupamento de regiões semelhantes nesse campo segmentado; 
- Permitir ao usuário a exploração do resultado, de forma a obter melhores resultados adicionando seu próprio conhecimento no processo.

Iremos manter o foco nos campos vetoriais em $2 \mathrm{D}$, porém mais à frente a técnica descrita é estendida ao contexto 3D.
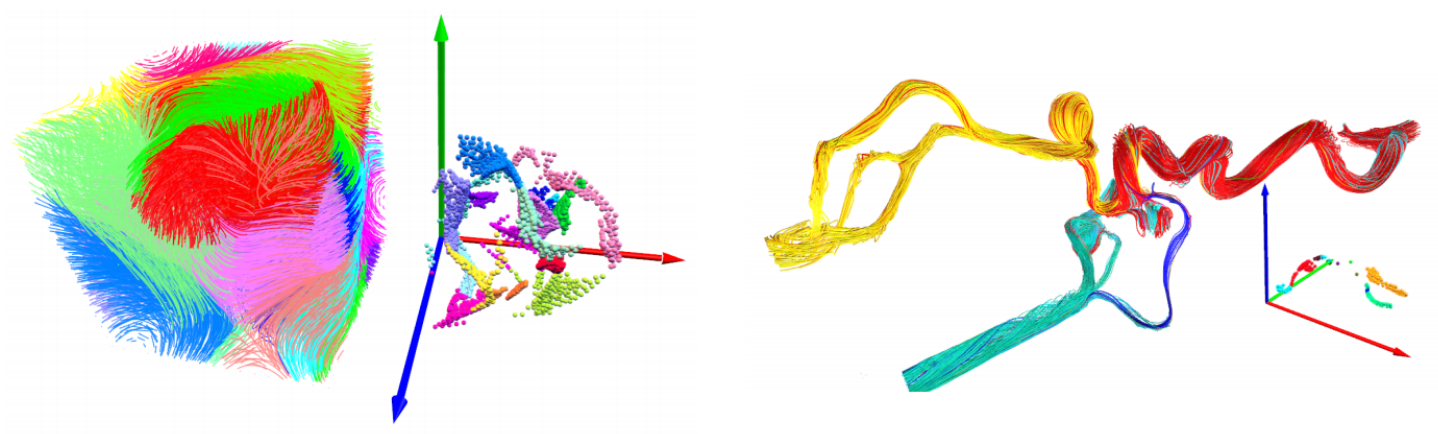

Figura 1.6: Segmentação de campos vetoriais usando streamlines geradas por Rössl e Theisel (extraído de [17]).

\subsection{Contribuições}

Como contribuições deste trabalho podemos citar:

- Uma nova maneira para se representar streamlines em alta dimensão;

- Um novo mecanismo que permite a intervenção do usuário no processo de segmentação.

\subsection{Organização do trabalho}

No capítulo 2 apresentamos o embasamento teórico do método: apresentamos primeiramente um resumo da técnica desenvolvida é visto na seção 2.2. Na seção 2.3 revisamos a teoria de streamlines e métodos para a sua integração, em seguida estudamos as características que podem ser extraídas do campo e a criação dos vetores de características. Na seção 2.4 revisamos a teoria do método de projeção multidimensional utilizado. Prosseguindo, na seção 2.5, falamos sobre o agrupamento, interação e resultado visual apresentado. No capítulo 3 apresentamos resultados da segmentação utilizando diferentes características, mostramos a influência da interação com usuário sobre os resultados e realizamos comparações do método criado com técnicas da litera- 
tura. Finalmente no capítulo 4, dissertamos sobre as principais contribuições, limitações e trabalhos futuros relativos à pesquisa desenvolvida. 


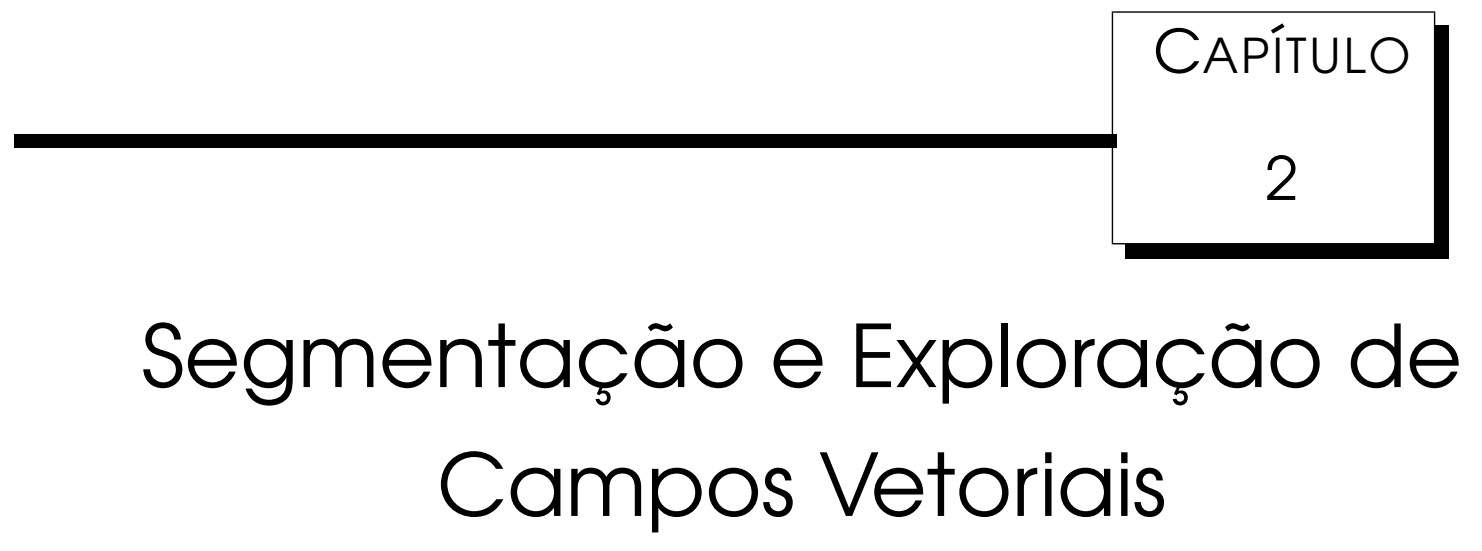

\subsection{Considerações Iniciais}

Neste capítulo apresentamos os detalhes do método desenvolvido. O nosso primeiro passo consiste na amostragem de streamlines, então iremos revisar a teoria sobre essas curvas integrais e comparar métodos para a geração das mesmas, culminando na decisão do método a ser utilizado. Em seguida, estudamos as características que podemos extrair do campo e a teoria para realizar essa extração. Relatamos como foram criados e tratados os vetores de características e, na sequência, apresentamos o método de projeção multidimensional utilizado. Por último, demonstramos a capacidade de interação do método e como a segmentação é apresentada ao usuário.

\subsection{Metodologia}

Após revisar as técnicas de segmentação de campos vetoriais existentes na literatura, partimos para a criação de um novo método, usando algumas das abordagens vistas como base para a nossa pesquisa.

Na figura 2.1 é mostrado um resumo do processo do método desenvolvido. Primeiro, são amostradas streamlines sobre o campo. Em seguida são extraídas características do mesmo e essas características são interpoladas 
sobre os pontos das curvas. De cada curva é criada uma distribuição de frequências de suas características e assim levamos o problema para a dimensão alta. Esse vetor de características é projetado em duas dimensões e agrupamentos são criados. Por fim, o campo vetorial é colorido de acordo com os agrupamentos das streamlines mais relevantes localmente. O usuário pode interagir com a projeção e com os agrupamentos para melhorar os resultados. Mais detalhes de cada passo serão descritos a seguir.

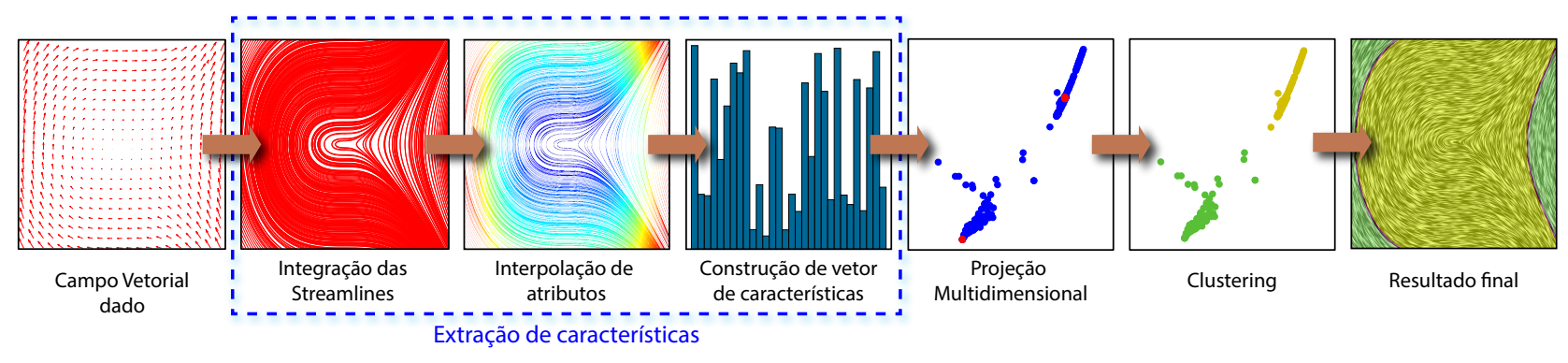

Figura 2.1: Fluxograma da técnica desenvolvida.

Em nossa proposta dividimos o campo em regiões de comportamento semelhante e, mais além, fornecemos ao usuário uma ferramenta flexível o suficiente para que essa segmentação seja relevante no contexto de interesse.

\subsection{Extração de Características}

Sejam os dados de entrada do método definidos como um campo vetorial sobre uma malha regular bidimensional. Segmentaremos regiões de comportamento semelhante desse campo, como regiões turbulentas, laminares ou próximas a pontos críticos; escolhemos então a unidade básica a ser classificada como um quadrilátero formado por quatro pontos adjacentes, os quais iremos nos referir por voxel. Será associado para cada voxel da malha um rótulo que o classifica e relaciona com os demais, ou seja, voxels de mesmo rótulo serão considerados como tendo campo vetorial local de comportamento semelhante.

Para determinar quais voxels se comportam de maneira semelhante, são necessárias mais informações que as recebidas como entrada. Com objetivo de obter informações, a extração de características é aplicada. Nesta etapa iremos coletar amostras do campo vetorial e selecionar quais propriedades devem ser extraídas do campo original. A partir desses dados e do conhecimento do usuário, a classificação será efetuada. Esse processo é explicitado abaixo. 


\subsubsection{Amostragem}

O primeiro passo do nosso algoritmo consiste na amostragem dos dados. Essa é realizada utilizando curvas suaves chamadas streamlines. Algumas definições são dadas a seguir [34, 35, 36].

Quatro tipos de curvas suaves são utilizadas em visualização de escoamentos:

- Streamline é uma linha tangente, em todos os seus pontos, ao campo vetorial em um dado instante;

- Pathline é o caminho real percorrido por uma dada partícula de fluido;

- Streakline é formada pelo conjunto de partículas que, em um certo instante anterior, passaram por um mesmo ponto no espaço. O efeito é semelhante ao de tinta injetada na mesma posição;

- Timeline é uma curva, em um determinado instante, formada por um conjunto de partículas de fluido. A curva se transforma conforme as partículas mudam de posição.

Enquanto streamlines podem ser convenientemente calculadas matematicamente, as outras curvas são obtidas com mais facilidade experimentalmente. Streamlines e timelines são curvas instantâneas (ou seja, existem em um determinado instante de tempo), enquanto streaklines e pathlines são temporais. Streamlines, pathlines e streaklines são conceitos idênticos se considerarmos um escoamento estável, mas diferem em escoamentos instáveis, ou seja, diferem quando se varia o tempo.

Seja um domínio bidimensional onde está definido um campo vetorial $\mathbf{U}\left(x_{i}, y_{i}, t_{i}\right)=(u, v)$, num certo instante $t_{i}$. Se streamlines são as curvas que são tangentes, em todo ponto, à direção do campo vetorial, temos que:

$$
\frac{d x}{d y}=\frac{u}{v} .
$$

A integral de (2.1), a partir de um ponto $\left(x_{0}, y_{0}, t_{i}\right)$ (chamado semente), resulta na equação da streamline no plano xy. Pela definição, pode-se dizer também que $\mathbf{U} \times \mathbf{d} \mathbf{s}=\mathbf{0}$, onde $\mathbf{d s}=(d x, d y)$ conforme visto na figura 2.2. Uma streamline pode ser definida como uma curva que corresponde à trajetória de uma partícula sem massa, a partir de um ponto inicial dado, considerando o campo vetorial como um escoamento estável. 


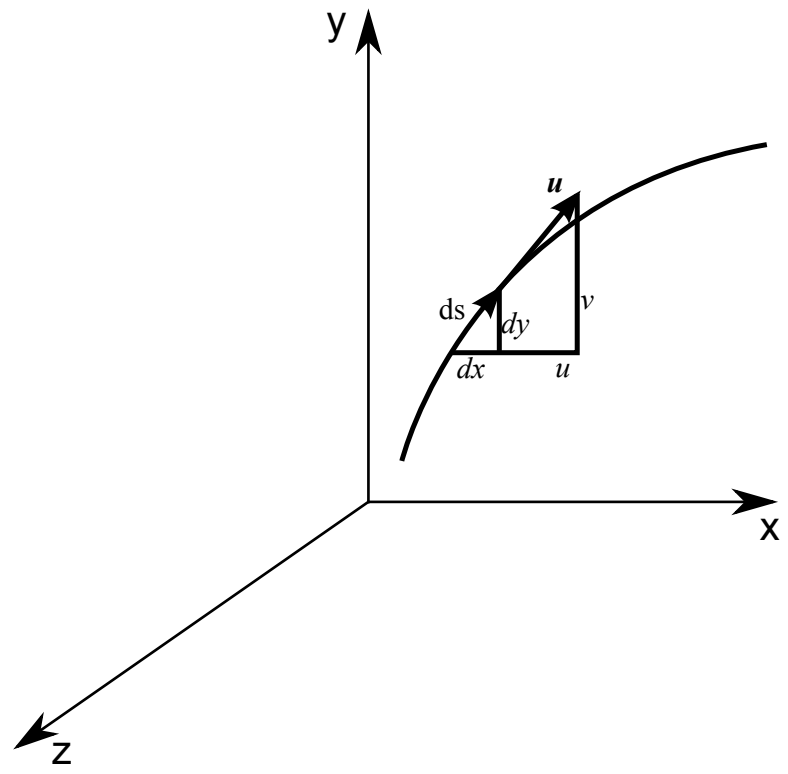

Figura 2.2: Streamline.

Uma pathline, ou deslocamento de uma partícula, é definida pela integração das componentes de velocidade:

$$
x=\int u d t, \quad y=\int v d t
$$

Então seja a função $U(x, y, t)$ a integração dada por (2.2) começando a partir de um ponto $\left(x_{0}, y_{0}, t_{0}\right)$ (também chamado semente). Podemos perceber que, se o campo não varia em função de $t$, as equações para pathline e streamline são exatamente as mesmas.

Uma streakline pode ser produzida experimentalmente pela liberação contínua de partículas marcadoras (por exemplo tinta, fumaça, ou bolhas) em um dado ponto.

Analogamente, podem ser calculadas superficies a partir do mesmo conceito das curvas, por exemplo, stream surfaces. As mesmas definições são aplicadas, porém devem ser criadas e mantidas estruturas, como malhas, para formar a superficie ou volume, resultado da ligação de várias sementes.

Usaremos streamlines para obter informações locais sobre o campo vetorial. Teremos então, em cada streamline, um conjunto de pontos relevantes em uma determinada região, relacionados ao fluxo descrito pelo campo vetorial. Outra importante contribuição do uso de streamlines como amostra inicial do método é observada quando se analisa a quantidade de streamlines em relação ao número de voxels: sabemos que teremos uma quantidade 
consideravelmente menor de streamlines do que voxels, e considerando que iremos continuar o processamento usando as mesmas como amostras, diminuímos assim o gargalo do método. A seguir analisamos alguns métodos de integração.

Consideremos o campo vetorial estático $U_{c}(x, y)=(y,-x)$; da equação 2.1 observa-se que:

$$
\frac{d x}{d y}=-\frac{y}{x} \quad \text { ou } \quad y d y=-x d x .
$$

Integrando a equação 2.3 temos:

$$
x^{2}+y^{2}=k,
$$

onde $k$ é uma constante. Obtemos a equação da circunferência, logo, a solução exata para uma streamline sobre o campo vetorial $U_{c}$ cuja semente é $\left(x_{0}, y_{0}\right)$ é uma circunferência de raio $k=\sqrt{x_{0}^{2}+y_{0}^{2}}$. Obviamente, a integração de uma streamline, em um campo vetorial discreto, não é exata, pois está sujeita a erros tanto do método de integração como devido a interpolações e a erros de precisão de máquina. Seja então o campo vetorial $U_{c}$ de domínio $D=$ $([-5 \ldots 5],[-5 \ldots 5])$ visto na figura 2.3. Integramos a streamline que começa em $(0,-1)$, visto em vermelho na figura 2.3 , de acordo com os métodos a seguir.

\section{Método de Euler}

O método de Euler é um método de primeira ordem [37] e pode ser usado para aproximar as integrais da equação 2.2 conforme:

$$
x_{i+1}=x_{i}+u_{i} d t, \quad y_{i+1}=y_{i}+v_{i} d t,
$$

onde $U$ é uma função tal que $U\left(x_{i}, y_{i}\right)=\left(u_{i}, v_{i}\right)$.

Exemplos de streamlines calculadas usando o método de Euler em $U_{c}$, na mesma semente $(0,-1)$ com três passos de tempo diferentes, podem ser vistos na figura 2.4. Visualmente percebemos que os resultados do método de Euler precisam de um passo de tempo baixo para se aproximarem da resposta exata.

Método de Heun

O método de Heun, também conhecido como método de Euler Modificado (ou Melhorado) [37], é um método preditor-corretor de segunda ordem. O 


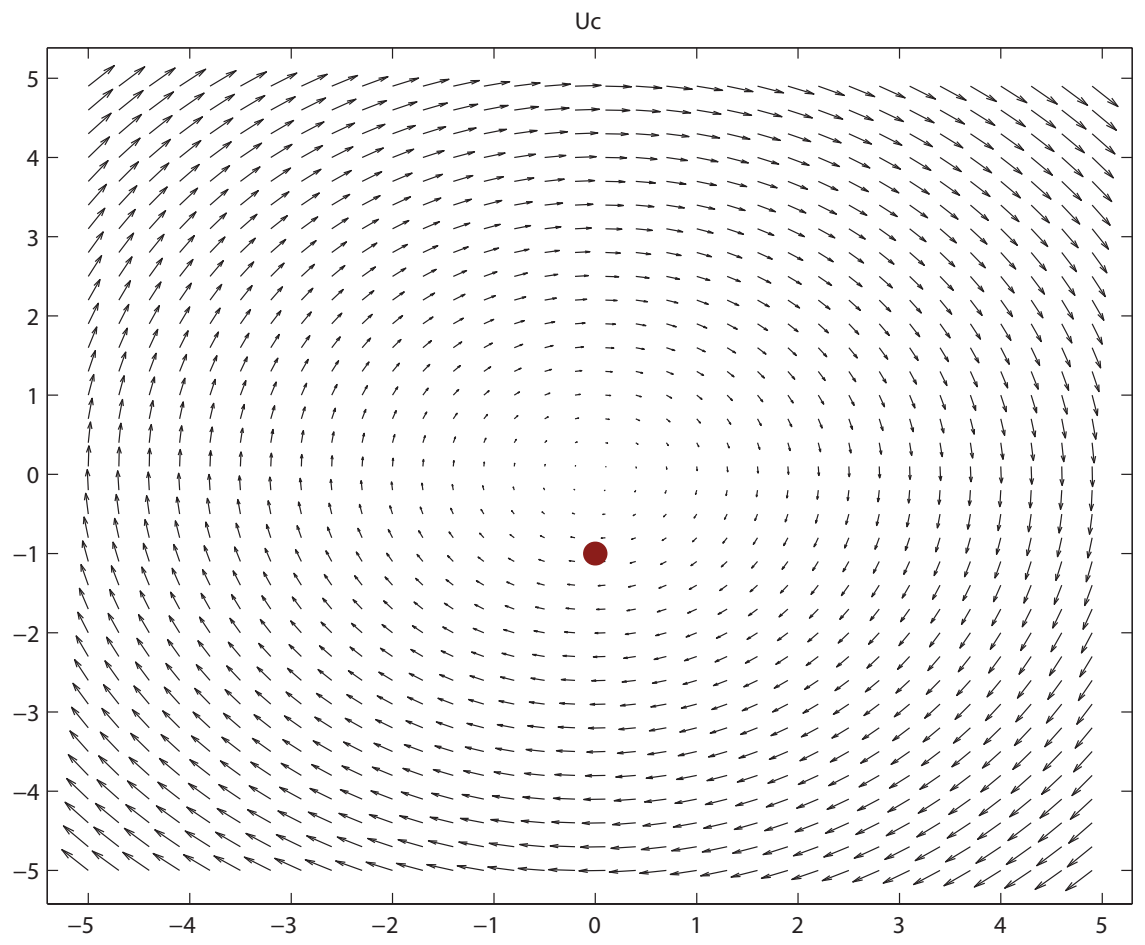

Figura 2.3: Campo vetorial teste para os métodos de integração.

nome Euler Modificado vem do fato que este método parte do resultado de um passo do método de Euler e em seguida faz um passo de correção:

$$
\begin{aligned}
& \tilde{x}_{i+1}=\quad x_{i}+u_{i} d t, \quad \tilde{y}_{i+1}=y_{i}+v_{i} d t, \\
& x_{i+1}=x_{i}+\frac{u_{i}+\tilde{u}_{i+1}}{2} d t, \quad y_{i+1}=y_{i}+\frac{v_{i}+\tilde{v}_{i+1}}{2} d t \text {, }
\end{aligned}
$$

onde $\tilde{u}_{i+1}$ e $\tilde{v}_{i+1}$ são as componentes $x$ e $y$ da velocidade calculadas no ponto $\left(\tilde{x}_{i+1}, \tilde{y}_{i+1}\right)$ respectivamente. O método de Heun é então uma extensão do método de Euler em que se usa um ponto intermediário para melhorar o resultado. Exemplos da integração usando o método de Heun no campo vetorial $U_{c}$ são vistos na figura 2.5. Analisando-se visualmente apenas, podemos dizer que o método se comporta de maneira parecida ao resultado exato, porém iremos analisar esses resultados de maneira quantitativa posteriormente.

Método de Runge-Kutta de quarta ordem (RK-4)

Seguindo a ideia de se usar pontos intermediários para melhorar a integração (vista no método anterior), no método clássico de Runge-Kutta de quarta 


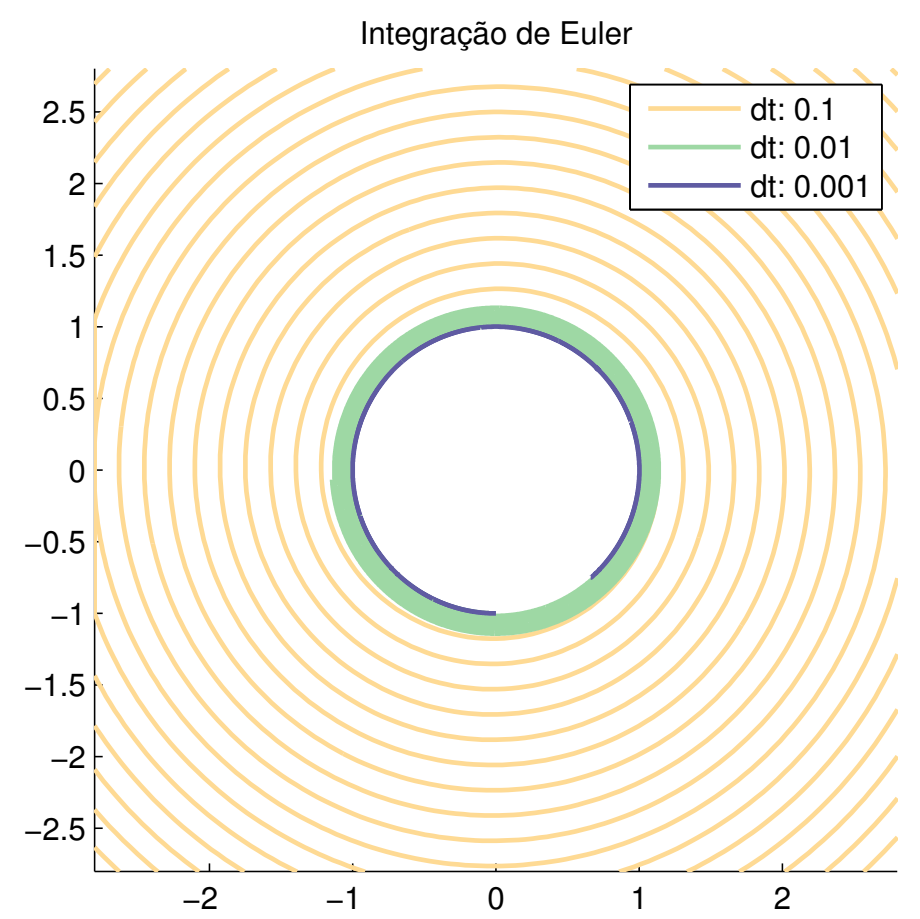

Figura 2.4: Resultado da integração usando método de Euler.

ordem [37] usaremos quatro pontos ao invés de dois para realizar a integração:

$$
\begin{array}{rlc}
x_{i+1} & = & x_{i}+\frac{k_{1}+2 k_{2}+2 k_{3}+k_{4}}{6} d t \\
k_{1} & = & U\left(x_{i}, y_{i}\right) \\
k_{2}= & U\left(x_{i}+\frac{k_{1}}{2} d t, y_{i}+\frac{d t}{2}\right) \\
k_{3}= & U\left(x_{i}+\frac{k_{2}}{2} d t, y_{i}+\frac{d t}{2}\right) \\
k_{4}= & U\left(x_{i}+k_{3} d t, y_{i} d t\right)
\end{array}
$$

Exemplos da integração utilizando o método de Runge-Kutta de quarta ordem no campo vetorial $U_{c}$ são mostrados na figura 2.6. Visualmente o método também parece se comportar de forma parecida ao resultado exato, mas a seguir faremos nossa análise quantitativa.

\section{Comparação}

Aproximando-se das curvas das figuras 2.4, 2.5 e 2.6 na figura 2.7 é possivel ver a diferença na precisão dos métodos de integração. Podemos perceber que os métodos de segunda e quarta ordem obtêm erro menor que o método de primeira ordem, conforme esperado. Mas para uma análise mais 
Integração de Heun

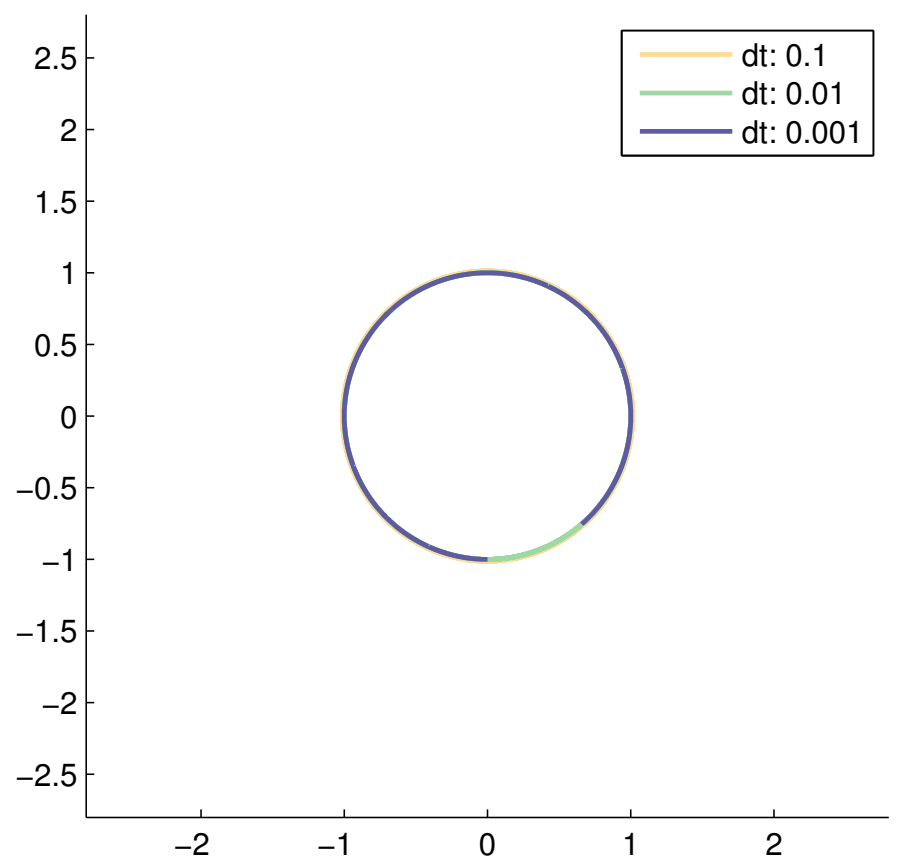

Figura 2.5: Resultado da integração com método de Heun.

concisa precisamos do erro numérico do método. O processo para calcular esse erro é mostrado no algoritmo 1. Dados de entrada são a streamline integrada em $U_{c}$ no ponto $s$, e o raio $r$ calculado como a distância entre $s$ e o centro $c$ do domínio de $U_{c}$. O erro de cada ponto $p$ da streamline é dado pela mínima distância entre $p$ e os pontos do círculo de raio $r$ centrado em $c$.

Entrada: Os pontos da streamline resultado da integração $P_{s}$, o raio do círculo $r$

Saida: Erro numérico de cada ponto integrado

1 Seja $\theta \subset \mathbb{R}, \theta=0$ até $2 * \pi$, passo 0.001 ;

$2 y_{c}=r * \sin (\theta)$;

$3 x_{c}=r * \cos (\theta)$;

4 Seja $C \subset \mathbb{R}^{2}$, onde $x=x_{c}$ e $y=y_{c}$;

5 para cada ponto $p$ em $P_{s}$ faça

$6 \quad D=$ distância euclidiana de $p$ para todo ponto em $C$;

$7 \quad \operatorname{Erro}(p)=$ valor mínimo em $D$;

8 fim

Algoritmo 1: Erro aproximado.

Considerando os campos vetoriais na sua forma discreta, o método de Heun exige duas interpolações a mais que o método de Euler, para cada passo. Já o método de Runge Kutta de quarta ordem exige oito interpolações a mais para cada passo. Essas interpolações melhoram o resultado do método, porém 


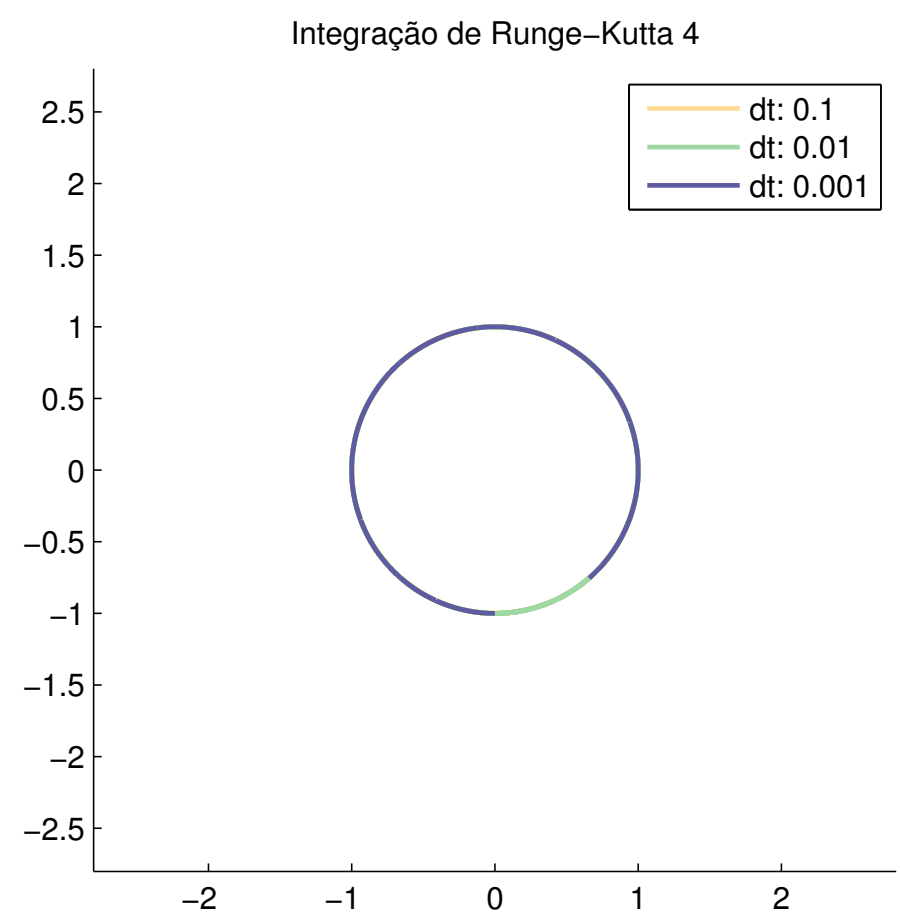

Figura 2.6: Resultado da integração usando RK-4.

terão impacto no tempo de execução. Sabendo que nosso método dependerá de quantidade considerável de integrações de streamlines, observemos as figuras 2.8, 2.9 e 2.10. As figuras 2.8 e 2.9 mostram os erros médios e máximos respectivamente, obtidos por cada um dos métodos em relação ao passo de tempo dado como entrada. Por último, a figura 2.10 demonstra o tempo de integração observado em cada um dos métodos, variando-se o número de sementes, ou seja, a quantidade de streamlines desejadas. Podemos perceber que o método de Runge-Kutta implementado é o mais preciso dos três, porém precisamos considerar o relevante aumento no tempo de computação observado na figura 2.10.

Assim, escolhemos o método de Heun como método de integração em nosso trabalho, considerando o tempo de execução e a precisão do método nesta decisão.

Com foco em obter relações relevantes em relação ao campo vetorial, iremos adicionar às nossas amostras conjuntos de características relevantes retiradas do próprio campo vetorial.

O método desenvolvido neste trabalho pode ser aplicado usando um conjunto de características quaisquer, porém os resultados dependerão de quão bem essas características descrevem as estruturas que queremos visualizar. Selecionamos algumas que consideramos relevantes ao contexto. 


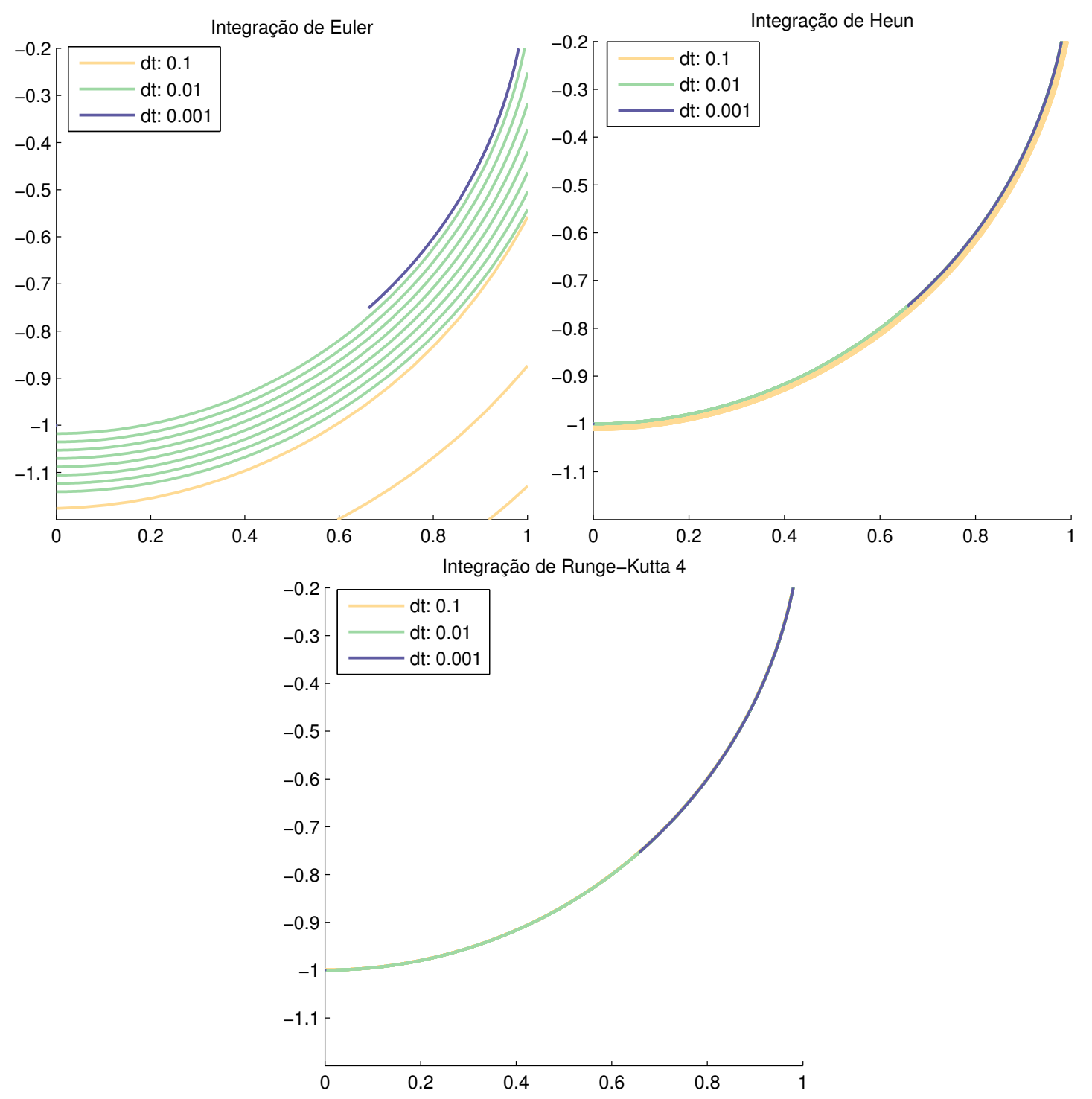

Figura 2.7: Ampliação nos resultados dos métodos de integração.

\subsubsection{Características}

Para que as streamlines sejam bem definidas em grupos significativos, ou seja, para que torne possivel diferenciá-las e classificá-las de forma coerente, foi definida uma estratégia de extração de características para as mesmas. Ou seja, a partir do campo vetorial dado e as streamlines obtidas do mesmo, foram realizadas operações para colher informações relevantes à classificação.

A seguir serão definidas as características selecionadas e o procedimento utilizado para obtê-las. Consideraremos o campo vetorial da figura 2.11 a como exemplo para a extração de características apresentadas nesta seção.

Sabendo que o campo vetorial descreve a ação de forças em um espaço, 


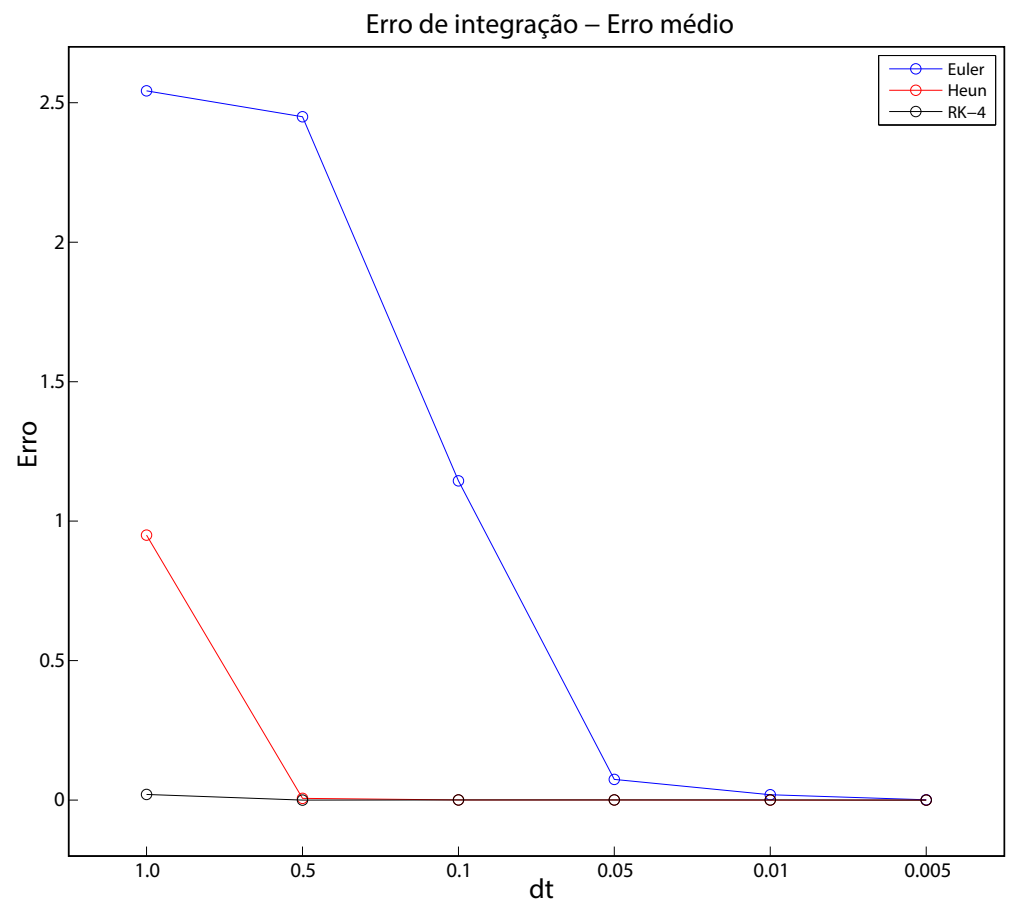

Figura 2.8: Erro médio.

temos que a magnitude dessas forças é uma medida de intensidade, ou seja, a magnitude de um ponto dará a intensidade do somatório das forças locais, e geometricamente, o comprimento do vetor resultante no ponto. O comportamento da magnitude em um campo vetorial é exemplificado na figura 2.12: a) observa-se um campo mais intenso em 1 do que em 2; a magnitude em 1 será maior que em 2 pois o campo é mais denso; b) o campo vetorial radial onde a magnitude é maior perto do centro; c) o campo uniforme onde a magnitude terá valor constante. Na figura 2.11 b vemos a magnitude do campo mostrado na figura 2.11a.

Seja $\mathbf{F}(x, y)=(u, v)$ um campo vetorial diferenciável em $\mathbb{R}^{2}$. O divergente de $\mathbf{F}$, denotado por $\nabla \cdot \mathbf{F}$ [34], é uma função real definida por:

$$
\nabla \cdot \mathbf{F}=\frac{\partial u}{\partial x}+\frac{\partial v}{\partial y}
$$

O divergente, aplicado a um ponto $P$ do campo vetorial $\mathbf{F}$ mede a taxa em que a matéria está sendo transportada para longe da vizinhança de $P$ [38], ou seja, mede a taxa de decaimento da densidade em um ponto. Podemos concluir que este operador carrega importantes informações relativas a fontes e sorvedouros. Alguns exemplos dessas propriedades estão representadas na 


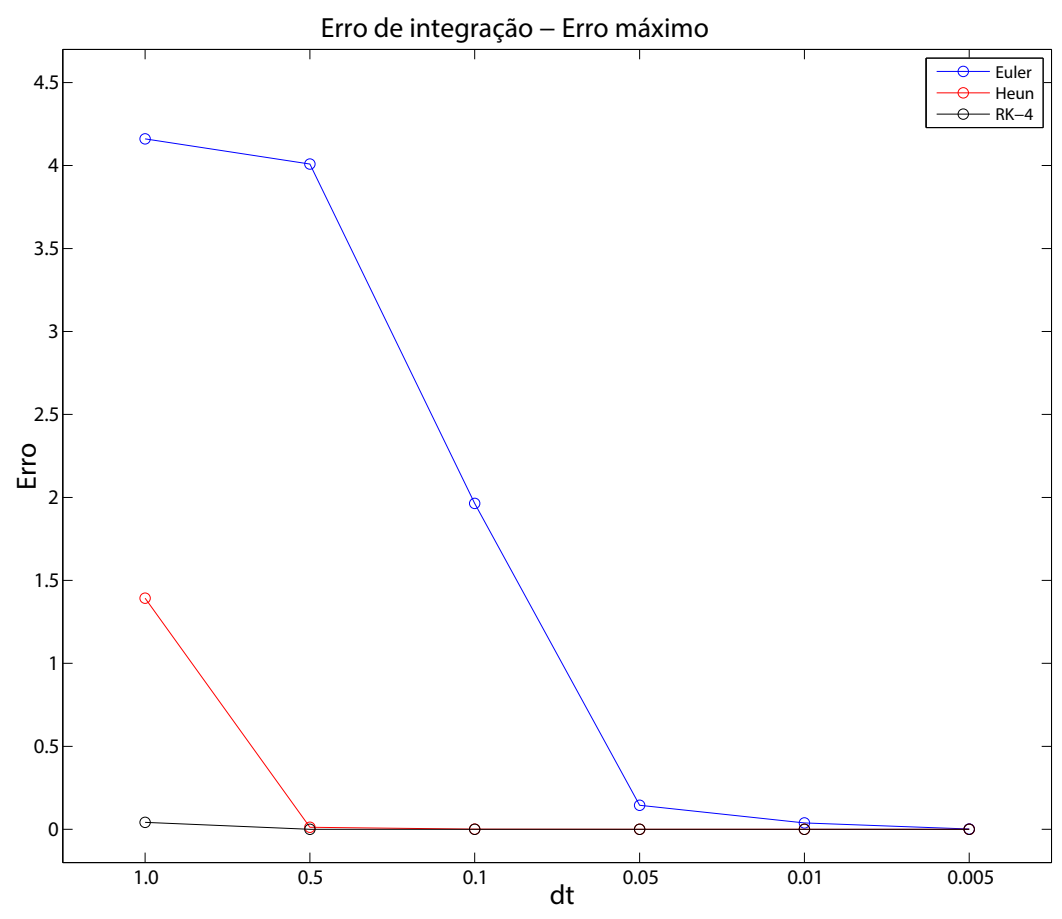

Figura 2.9: Erro máximo.

figura 2.13: a) campo vetorial convergindo para o ponto: divergente negativo; b) campo vetorial divergindo do ponto: divergente positivo; $c$ ) e $d$ ) não há convergência ou divergência do campo vetorial: divergente é zero. A figura $2.11 \mathrm{c}$ exemplifica o divergente no campo da figura 2.11a.

Vorticidade, ou densidade de circulação [39], é definida como o rotacional da velocidade, e normalmente denotada pelo símbolo $\omega$. Assim, sendo F a mesma função vista anteriormente, temos que

$$
\omega=\nabla \times \mathbf{F}=\frac{\partial v}{\partial x}-\frac{\partial u}{\partial y} .
$$

A vorticidade do campo vetorial indica o quanto um fluido rotaciona localmente e a direção dessa rotação [38]. Como estamos interessados em descobrir estruturas semelhantes no campo vetorial, em alguns de nossos exemplos preferimos eliminar a direção da rotação dessa característica utilizando $\|\omega\|$; assim, buscamos identificar estruturas de vórtices como um tipo de estrutura independentemente da direção da rotação. A figura $2.11 \mathrm{~d}$ mostra a magnitude da vorticidade sobre o campo exemplo.

O critério $\lambda_{2}$ definido por Jeong e Hussain em [28, 40] é um critério popular que tem como objetivo a identificação de vórtices em escoamentos. $\lambda_{2}$ baseiase na observação que o conceito de localizar vórtices em um plano procurando 


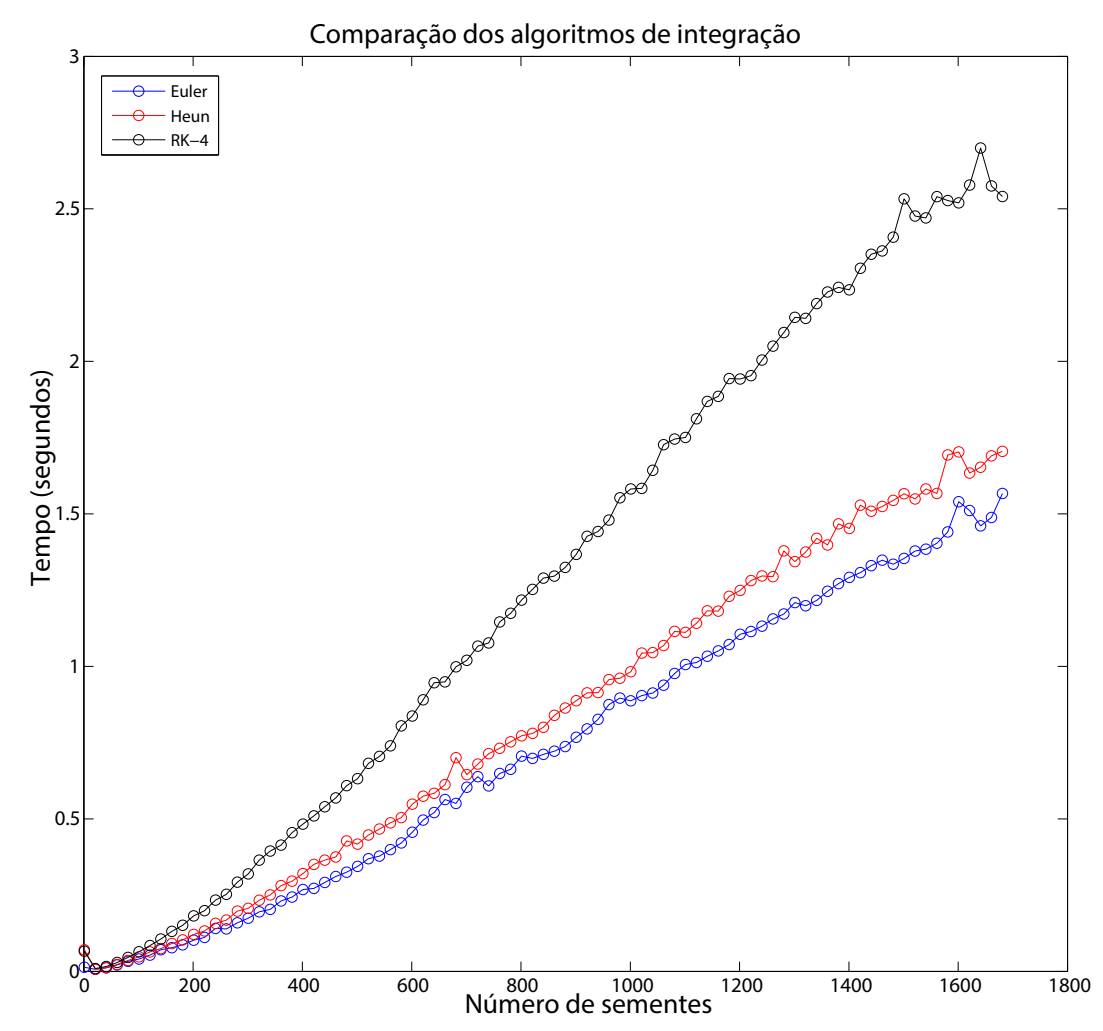

Figura 2.10: Tempo de processamento.

mínimos locais de pressão falha quando estão presentes deformações instáveis (unsteady straining) e efeitos viscosos.

A proposta do critério de Jeong e Hussain então é remover esses efeitos e obter um método mais eficiente para a detecção de vórtices. Para remover esses efeitos, decompõe-se o tensor gradiente da velocidade $\mathbf{J}=\nabla \mathbf{V}$ em sua parte simétrica, o tensor taxa de deformação (rate of deformation ou strainrate tensor) $\mathrm{S}$, e sua parte antissimétrica, o tensor de rotação (spin tensor) $\Omega$, e considera-se apenas a contribuição de $\mathbf{S}^{2}+\Omega^{2}$. Os tensores são calculados por

$$
S=\frac{\mathbf{J}+\mathbf{J}^{T}}{2}, \quad \Omega=\frac{\mathbf{J}-\mathbf{J}^{T}}{2} .
$$

Um vórtice é definido então em regiões onde $S^{2}+\Omega^{2}$ tem dois autovalores negativos. Nota-se que esses autovalores serão sempre reais pois $\mathbf{S}^{2}+\Omega^{2}$ é simétrica. Sejam então $\lambda_{1}, \lambda_{2}$ e $\lambda_{3}$ os autovalores de modo que $\lambda_{1} \geq \lambda_{2} \geq \lambda_{3}$. Pela definição, somente é preciso que $\lambda_{2}<0$ para que se esteja sobre um vórtice.

Embora esse critério aplicado num campo vetorial resulte em um resultado verdadeiro ou falso, podemos utilizar $\lambda_{2}$, o segundo autovalor, como propriedade; assim obtém-se informação sobre regiões externas ao vórtice, no seu 


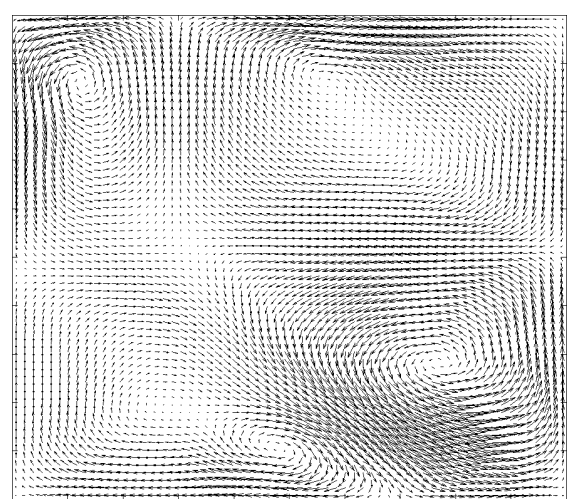

(a) Exemplo de campo vetorial.

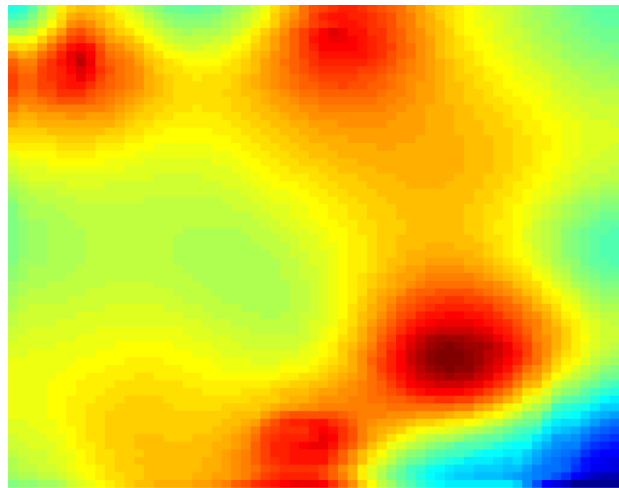

(c) Divergente.

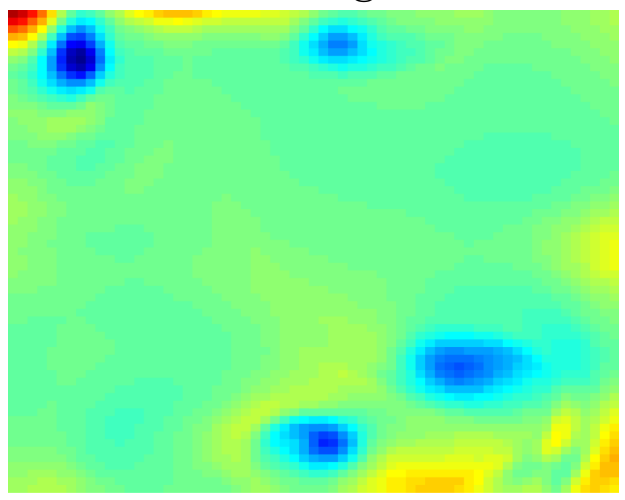

(e) Critério $\lambda_{2}$

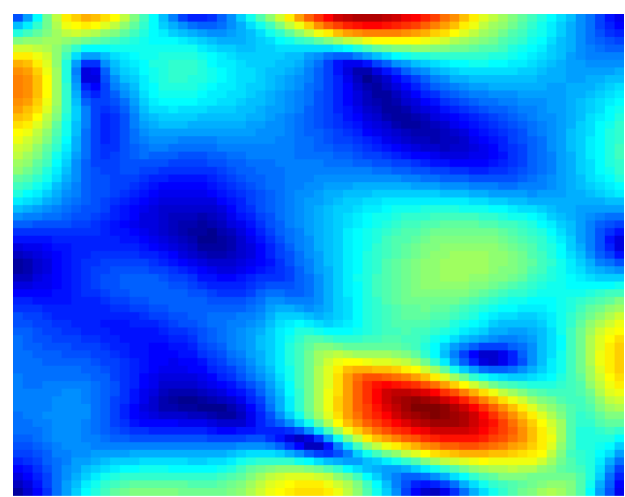

(b) Magnitude.

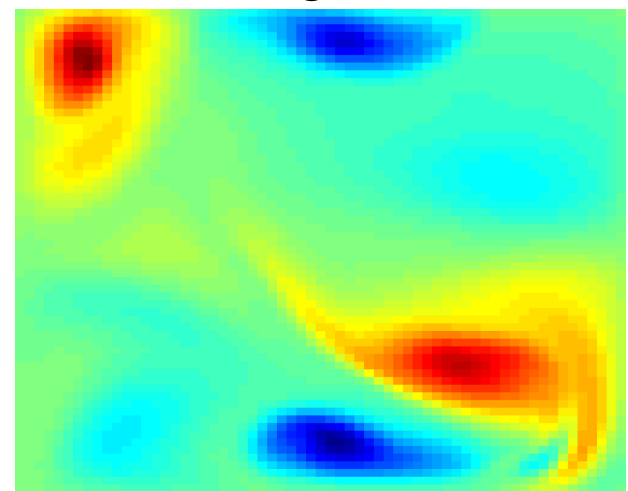

(d) Vorticidade.

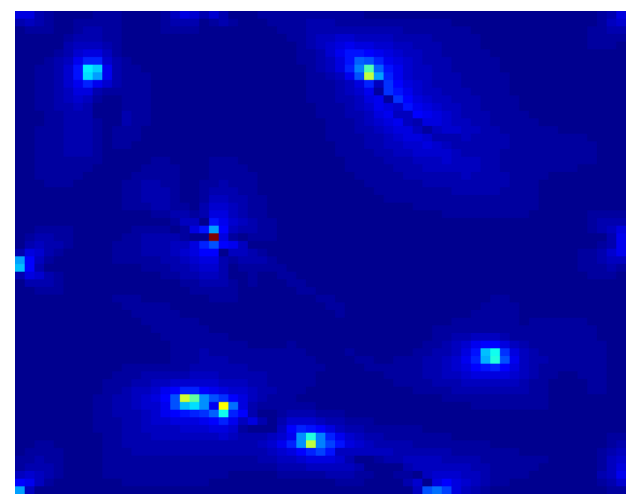

(f) Curvatura.

Figura 2.11: Campo vetorial inicial e campos escalares característicos. Cores quentes representam valores maiores e cores frias valores menores. 
a)

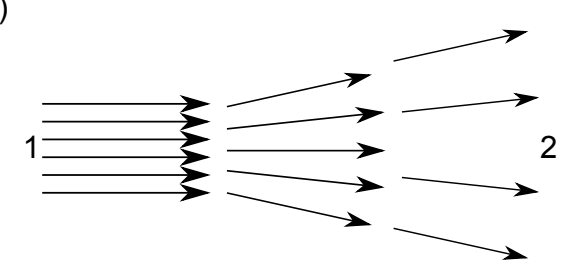

b)

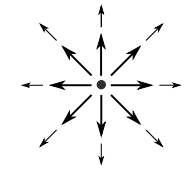

c)

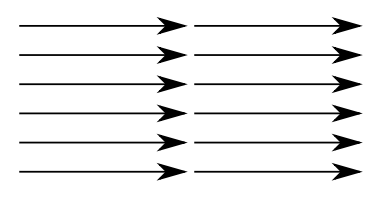

Figura 2.12: Exemplos do conceito de magnitude de campos vetoriais.

a)

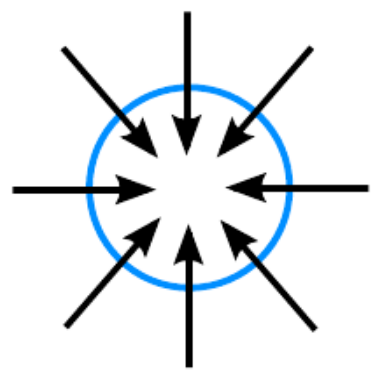

c)

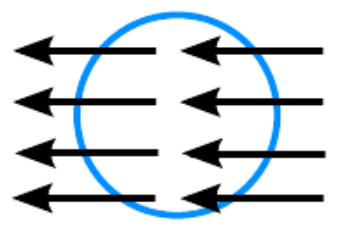

b)

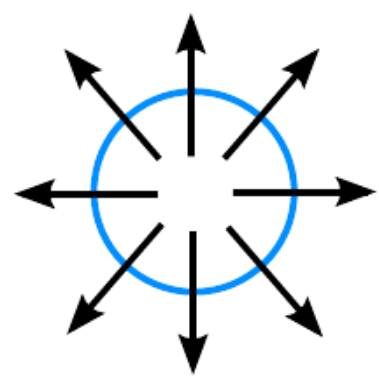

d)

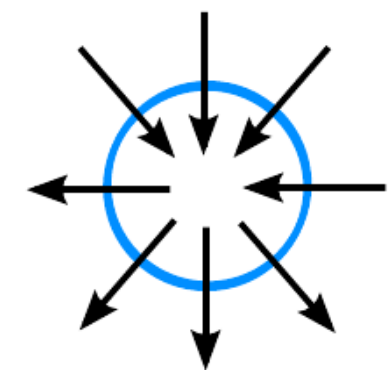

Figura 2.13: Exemplos com operador divergente.

bordo e interior, não só as regiões de vórtices. Um exemplo do comportamento desse autovalor sobre o campo vetorial pode ser observado na figura 2.11e.

Uma importante propriedade, frequentemente explorada em outras pesquisas no contexto de campos vetoriais é a curvatura [41]. Em McLoughlin et al. [18] a curvatura $\mathbf{C}$ do campo vetorial dado é calculada como

$$
\mathbf{C}=\frac{\mathbf{v} \times \mathbf{a}}{|\mathbf{v}|^{3}}
$$

onde $\mathbf{v}$ é a velocidade local, e a a aceleração local (calculada como v( $\nabla \mathbf{v})$ ). A curvatura é uma medida que informa quanto uma curva se desvia de uma linha reta [18]. Porém, conforme visto acima, não precisamos integrar a curva em um ponto para obter a sua curvatura se possuímos o campo vetorial sobre o domínio. A magnitude da curvatura sobre o campo foi adotada em nossos experimentos. A figura $2.11 \mathrm{f}$ demonstra a magnitude da curvatura sobre o campo exemplificado. Na mesma figura podemos observar a forte relação entre 
a curvatura e os pontos críticos do campo.

Novamente baseando-se em [18] temos que a tortuosidade é uma medida relativa de quão distante de uma linha reta é a curva, onde a linha é formada pelos pontos inicial e final da curva. Considerando uma streamline $S$ e sendo $P$ o conjunto dos $N$ pontos que formam $S$, temos que a tortuosidade de $S$ é dada por

$$
T=\frac{1}{\|P(N)-P(1)\|} \sum_{i=1}^{N-1}\|P(i+1)-P(i)\| .
$$

Com essa medida temos como diferenciar as streamlines em relação à sua geometria, tendo assim mais informação sobre o comportamento do fluxo local amostrado.

Finalmente temos mais uma propriedade geométrica, a torção [18]. Semelhante à curvatura, a torção pode ser obtida diretamente sobre o campo:

$$
\tau=\frac{(\mathbf{v} \times \mathbf{a}) \cdot((\nabla \mathbf{a}) \mathbf{a})}{|\mathbf{v} \times \mathbf{a}|^{2}}
$$

Porém essa característica não tem sentido em duas dimensões já que mede quanto uma curva sai do plano osculador. Mantemos a ideia de torção em mente para a versão desta mesma técnica em 3D.

Para se realizar a extração das características descritas é necessária uma ferramenta que permita o cálculo de derivadas parciais na malha onde se encontra o campo vetorial discreto. Esse cálculo foi feito utilizando o método das diferenças finitas. Nas bordas do domínio utilizamos os métodos de diferenças finitas progressiva e regressiva:

$$
\frac{d u}{d x}\left(x_{0}\right)=\frac{u\left(x_{0}+\Delta x\right)-u\left(x_{0}\right)}{\Delta x}, \quad \frac{d u}{d x}\left(x_{0}\right)=\frac{u\left(x_{0}\right)-u\left(x_{0}-\Delta x\right)}{\Delta x},
$$

onde $u$ é a função, em nosso caso, do campo vetorial que queremos derivar em um ponto $x_{0}$ por uma diferença discreta finita de $\Delta x>0$. Na parte interna do domínio usamos diferenças finitas centradas:

$$
\frac{d u}{d x}\left(x_{0}\right)=\frac{u\left(x_{0}+\Delta x\right)-u\left(x_{0}-\Delta x\right)}{2 \Delta x} .
$$

As características que são definidas sobre o campo vetorial são interpoladas sobre os pontos de cada streamline usando a interpolação bilinear [37]. A seguir realizamos mais um passo de pré-processamento dos nossos dados. 


\subsubsection{Distribuição de Frequências}

Neste momento, nosso conjunto de dados está definido como um grupo de curvas e, para cada curva, um conjunto de características. Se comparássemos as streamlines ponto a ponto, ou por segmentos, duas streamlines iguais porém sendo imagens espelhadas - seriam consideradas diferentes. Para evitar esse problema iremos adotar a estratégia de representar os nossos dados com distribuição de frequências.

Para cada característica, descobrimos o máximo max e mínimo min observado, e dividimos esse intervalo (min, max) em um determinado número de subintervalos $N_{d}$ (também chamados bins). Em seguida é criada uma distribuição de frequências para cada característica de cada streamline. Temos então nossas streamlines definidas como distribuições de frequências de suas características independentemente de sua posição no espaço.

Para evitar que streamlines com número de pontos diferentes sejam tratadas de forma diferente, cada distribuição de frequências tem o valor em cada subintervalo dividido pelo número de pontos da sua streamline, normalizando os vetores.

Assim representamos as curvas em dimensão alta: as distribuições podem ser vistas como vetores que representam as características observadas nas curvas, os quais chamaremos de vetores de características. O algoritmo 2 apresenta o passo a passo teórico deste processo.

A figura 2.14 ilustra diferentes distribuições de frequências para as respectivas streamlines. As características usadas foram curvatura, vorticidade e magnitude da velocidade com distribuições de cinco subintervalos. Podemos observar que existe diferença nos histogramas da figura 2.14 mesmo utilizando apenas cinco subintervalos. No histograma vermelho, que representa uma curva que passa sobre vórtices, observa-se variação na curvatura, não observadas nos outros histogramas, enquanto as outras características permanecem baixas, diferindo dos histogramas verde e azul. Obviamente, em distribuições com mais subintervalos essa diferença seria intensificada.

Neste momento podemos manter em memória um conjunto de índices para cada streamline que representam por quais voxels as mesmas atravessam, e liberar da memória os pontos que compõem as curvas, eliminando um gargalo do método.

Agora é preciso citar um tema muito importante para a definição de $N_{d}$ : o 
Entrada: Conjunto de $N_{\text {str }}$ streamlines $S, N_{\text {car }}$ características $C$, número de subintervalos $N_{d}$

Saida: Distribuições de frequências $D_{f}$ representando cada streamline

$1 D_{f}=$ matriz nula de $N_{s t r} \times N_{c a r} \times N_{d}$;

2 para cada Streamline $s_{i}$ de $S$ faça

$3 \quad N_{p}=$ numero de pontos em $s_{i}$;

4

5

para cada Característica $c_{j}$ de $C$ faça

$\min _{c}=$ valor mínimo em $c\left(s_{i}\right)$;

$\max _{c}=$ valor máximo em $c\left(s_{i}\right)$;

tamanho_bin $=\left(\max _{c}-\min _{c}\right) / 2$;

para cada ponto $p$ de $s_{i}$ faça

$k=0$;

enquanto $k<N_{d} E$ não achou bin faça

$I=\left[\min _{c}+\right.$ tamanho_bin $* k, \min _{c}+$ tamanho_bin $\left.*(k+1)\right]$;

se $c_{j}(p)$ pertence ao intervalo $I$ então

$D_{f}[i, j, k]=D_{f}[i, j, k]+1$

Achou bin;

14
15

16

17

18

19

20

21

22

23 fim

Algoritmo 2: Representação teórica da obtenção dos vetores que representam as streamlines na dimensão alta. 

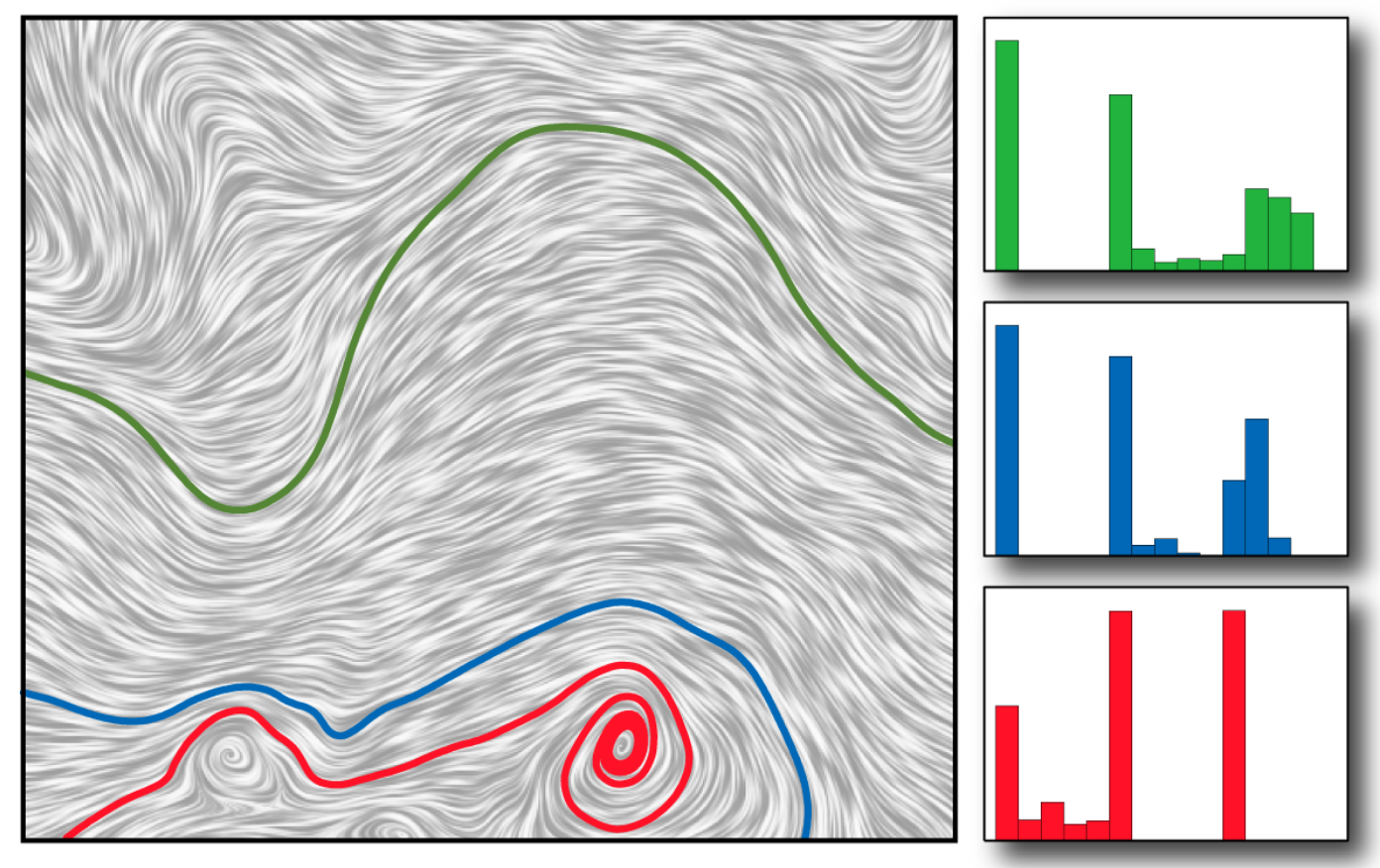

Figura 2.14: Histogramas representando o vetor de características em dimensão alta de três streamlines.

que alguns chamariam de "maldição da dimensionalidade". Beyer et al. [44] conclui que, em uma ampla coleção de distribuições de dados, à medida que a dimensionalidade aumenta, a diferença entre os vizinhos mais próximo e mais distante fica cada vez menor. Em outras palavras, o contraste das distâncias entre diferentes pontos se torna inexistente. Devemos ter em mente esse princípio ao selecionar um valor para $N_{d}$, já que nosso conjunto na dimensão alta são distribuições de frequências de $N_{d}$ subintervalos cada um; ou seja, o número de dimensões depende diretamente de $N_{d}$.

\subsection{Projeção multidimensional}

A habilidade para visualizar e interagir com dados em dimensão alta é limitada tanto pelas ferramentas que possuímos quanto pela percepção de distância humana. Esse problema pode ser resolvido realizando-se um mapeamento que represente os dados de forma significativa na área de visualização alvo, como um tela de computador [45].

Técnicas de projeção multidimensional fazem o mapeamento de dados em dimensão alta para uma dimensão menor, geralmente um plano visual de uma a três dimensões, de modo que a distância entre os dados seja preservada ao 
máximo possível.

Um método simples para se realizar projeção é usando Análise de Componentes Principais (Principal Component Analysis, PCA) [46] onde a redução dimensional ocorre projetando-se dados na direção em que possuem maior variância. Podemos citar outra técnica chamada Least Square Projection (LSP) [27] baseada na aproximação por mínimos quadrados. Nela resolve-se um sistema linear esparso baseado na vizinhança entre os pontos para criar a projeção dos pontos no espaço visual. As técnicas PCA e LSP foram estudadas, porém não foram selecionadas como a técnica de projeção a ser utilizada, pois o método descrito a seguir é mais eficiente, possui resultados mais precisos, permite a interação com o usuário e necessita de um número limitado de pontos de controle [47].

\subsubsection{Local Affine Multidimensional Projection}

Local Affine Multidimensional Projection (LAMP) [47] é um método local que também usa pontos de controle no espaço visual para mapear os outros pontos do domínio para esse espaço. Abaixo fazemos a revisão teórica da técnica.

Para cada ponto é definida uma transformação afim para o mapeamento do ponto. Seja então $x$ um elemento dos dados $X, x \in \mathbb{R}^{m}$ e seja $x_{i}$ o i-ésimo elemento de um subconjunto $X_{s}=\left\{x_{1}, \ldots, x_{k}\right\}$ de pontos de controle selecionados de $X$. Seja então o conjunto correspondente de $X_{s}$ no espaço visual chamado $Y s=\left\{y_{1}, \ldots, y_{k}\right\}$. A LAMP resolve um problema de minimização que encontra a melhor transformação afim para cada ponto $f(p)=p M+t$ que minimiza

$$
\sum_{i} \alpha_{i}\left\|f\left(x_{i}\right)-y_{i}\right\|^{2}, \text { sujeito a } \quad M^{T} M=I
$$

onde a matriz $M$ e o vetor $t$ são incógnitas, $I$ é a identidade e $\alpha_{i}$ são os pesos escalares definidos como

$$
\alpha_{i}=\frac{1}{\left\|x_{i}-x\right\|^{2}}
$$

Em seguida, escolhendo as derivadas com respeito a $t$ iguais a zero, pode-se escrever

$$
t=\tilde{y}-\tilde{x} M, \quad \tilde{x}=\sum_{i} \frac{\alpha_{i} x_{i}}{\alpha}, \quad \tilde{y}=\sum_{i} \frac{\alpha_{i} y_{i}}{\alpha}
$$


onde $\alpha=\sum_{i} \alpha_{i}$. Então reescrevemos nosso problema de minimização como

$$
\sum_{i} \alpha_{i}\left\|\hat{x}_{i} M-\hat{y}_{i}\right\|^{2}, \text { sujeito a } M^{T} M=I
$$

onde $\hat{x}_{i}=x_{i}-\tilde{x}$ e $\hat{y}_{i}=y_{i}-\tilde{y}$. Reescrevendo essa nova forma matricialmente temos

$$
\|A M-B\|_{F}, \text { sujeito a } M^{T} M=I
$$

onde $\|\cdot\|_{F}$ é a norma de Frobenius e

$$
A=\left[\begin{array}{c}
\sqrt{\alpha_{1}} \hat{x_{1}} \\
\vdots \\
\sqrt{\alpha_{k}} \hat{x_{k}}
\end{array}\right], \quad B=\left[\begin{array}{c}
\sqrt{\alpha_{1}} \hat{y_{1}} \\
\vdots \\
\sqrt{\alpha_{k}} \hat{y_{k}}
\end{array}\right] .
$$

Esse problema possui solução dada por

$$
M=U V, \quad A^{T} B=U D V
$$

onde $U D V$ é a Singular Value Decomposition (SVD) de $A^{T} B$. Assim encontra-se $y$ como

$$
y=f(x)=(x-\tilde{x}) M+\tilde{y} .
$$

Esses mapeamentos seguirão a configuração dos pontos de controle; assim, ao mover um ponto de controle altera-se a projeção, permitindo que o usuário melhore o resultado da projeção com os conhecimentos que possui do contexto dos dados a serem projetados. Inicialmente pode-se escolher os pontos de controle randômicos, já que se espera que o método preserve as distâncias ao máximo possível. Em nossa abordagem preferimos por uma estratégia fixa dos pontos de controle, onde basicamente, o domínio é dividido em $k$ partições e de cada partição é selecionada como ponto de controle a moda das suas amostras. A LAMP foi escolhida como a nossa técnica de projeção pela sua rapidez, interatividade e precisão nos resultados. Após projetar os dados no espaço visual, estamos prontos para classificar e visualizar a segmentação conforme visto a seguir.

\subsection{Classificação e Visualização}

Após a projeção, os dados coletados encontram-se no espaço visual de dimensão 2. A partir daí, nosso problema de classificação é resolvido de maneira 
simples. Os pontos do espaço visual são agrupados por um algoritmo de agrupamento ou por interação com o usuário, e assim temos um rótulo para cada streamline. Agora, trazemos essa classificação de volta para os nossos voxels observando quais streamlines os atravessam. Se um voxel é mais atravessado por streamlines de um determinado grupo, o mesmo pertence àquele grupo. O algoritmo que utilizamos para realizar o agrupamento automático é visto a seguir.

\subsubsection{Algoritmo de Agrupamento}

Para o algoritmo de agrupamento, escolhemos um método hierárquico aglomerativo chamado método de Ward ou Mínima Variância [48, 49], uma técnica de agrupamento hierárquica. Em seu livro, Jain e Dubes [50] fizeram estudos comparativos e afirmaram que este algoritmo supera outros algoritmos hierárquicos. Além disso, podemos tirar proveito do comportamento deste algoritmo hierárquico que permite que o usuário aumente o número de agrupamentos que deseja, formando novos grupos pela subdivisão dos já calculados. Ou seja, conforme o usuário aumenta o número de agrupamentos, veremos no resultado da segmentação a subdivisão de estruturas segmentadas. Podemos dizer que o algoritmo proporciona a capacidade de refinamento da segmentação. Segundo Rasmussen [51], o método de Ward segue os seguintes passos:

1. Identificar os dois pontos mais próximos e combiná-los em um agrupamento. Quando dois pontos são agrupados é criado um ponto central que representará o agrupamento.

2. Pontos já agrupados são removidos dos próximos testes, e o ponto central é usado para representá-los.

3. Se mais combinações são necessárias, retornar ao passo 1.

O método de Ward escolhe o par que minimiza a variância entre grupos. Quando dois pontos $P_{i}$ e $P_{j}$ são agrupados o aumento na variância $V_{i j}$ é calculado:

$$
V_{i j}=\frac{n_{i} n_{j}}{n_{i}+n_{j}} d_{i j}^{2}
$$

onde $n_{i}$ é o número de pontos no agrupamento de $P_{i}$ e $d_{i j}^{2}$ é a distância Euclidiana ao quadrado entre os dois pontos. O ponto central do par agrupado que 
representará o agrupamento é dado por:

$$
C=\frac{n_{i} P_{i}+n_{j} P_{j}}{n_{i}+n_{j}}
$$

O método de Ward tende a criar agrupamentos circulares em 2D, o que condiz com o tipo de algoritmo que precisamos.

\subsubsection{Visualização}

A visualização dos resultados em 2D é facilmente aplicada pintando os voxels com as mesmas cores representadas nos agrupamentos. Para um melhor entendimento e melhoria dos resultados, aplicamos um algoritmo de suavização [52] e adicionamos o LIC [12] do campo vetorial original à imagem do resultado final. Podemos ver na figura 2.15 o processo envolvido. Nosso resultado é suavizado e então o LIC é adicionado para formar o resultado final. Temos no final um resultado suave e que é intuitivo, de forma que o LIC informa o usuário sobre o comportamento do campo em relação à segmentação produzida.

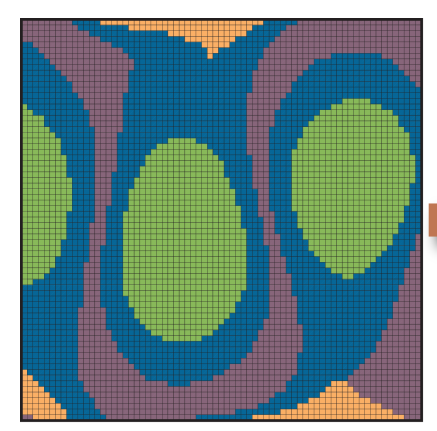

Segmentação

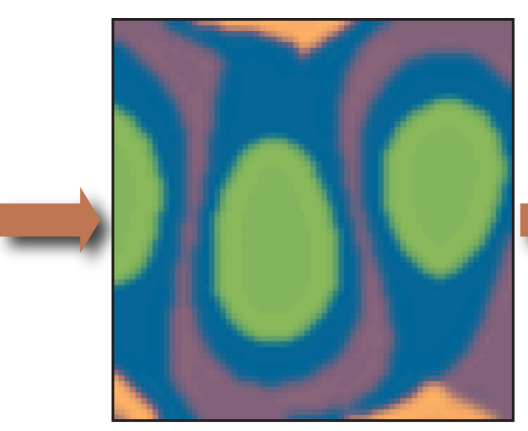

Suavização

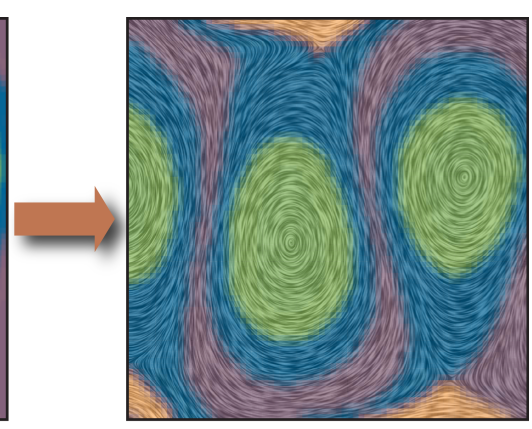

LIC

Figura 2.15: Pipeline de visualização da segmentação 2D.

No caso 3D, o método é o mesmo, até o momento da visualização, onde o problema é complicado pela oclusão entre os grupos. A solução encontrada é renderizar as superficies que dividem os grupos adjacentes. A informação sobre o campo original é adicionada ao resultado final, usando-se algumas streamlines de cor igual às cores dos grupos a que pertencem resultados do agrupamento. 


\subsection{Interação}

Um dos objetivos definidos no início deste trabalho foi a abordagem utilizando o conhecimento do usuário. Interação pode ser realizada em três etapas do nosso método explicitadas abaixo e discutidas a seguir:

- na seleção de características a serem extraídas;

- no processo de agrupamento;

- utilizando os pontos de controle para re-projeção.

O primeiro processo se refere a quais características o usuário irá selecionar para a sua visualização, ponderando sobre o campo vetorial passado e sobre as estruturas que pretende capturar. O usuário pode escolher quais caracteristicas considera relevantes, para inserir no processo, e quais considera irrelevantes, que podem ser removidas.

O segundo processo permite que o usuário possa fazer ou corrigir o agrupamento manualmente. Informação sobre a correspondência entre o ponto no espaço visual e a streamline sobre o campo vetorial é fornecida, e assim o usuário dispõe de alguma informação além das relações vistas no espaço visual para inserir um agrupamento manualmente. Além disso, o usuário pode explorar o campo vetorial selecionando manualmente na projeção apenas pontos que tem interesse. Essa interação é mostrada na figura 2.16.

O terceiro processo permite que o usuário altere o resultado final manipulando pontos de controle no espaço visual, re-projetando os pontos e realizando o agrupamento novamente para obter um resultado corrigido conforme seu contexto. Assim, o usuário pode corrigir erros, separar grupos e refinar seus resultados de forma a ressaltar estruturas que considere interessante.

Finalmente, o usuário pode selecionar alguns pontos da projeção para visualizar as regiões no campo vetorial que os pontos em 2D representam; assim, pode determinar quais regiões da projeção deve alterar para corrigir segmentações equivocadas. O usuário pode interferir diretamente no resultado, seja mudando o agrupamento ou selecionando a região de interesse na projeção. 


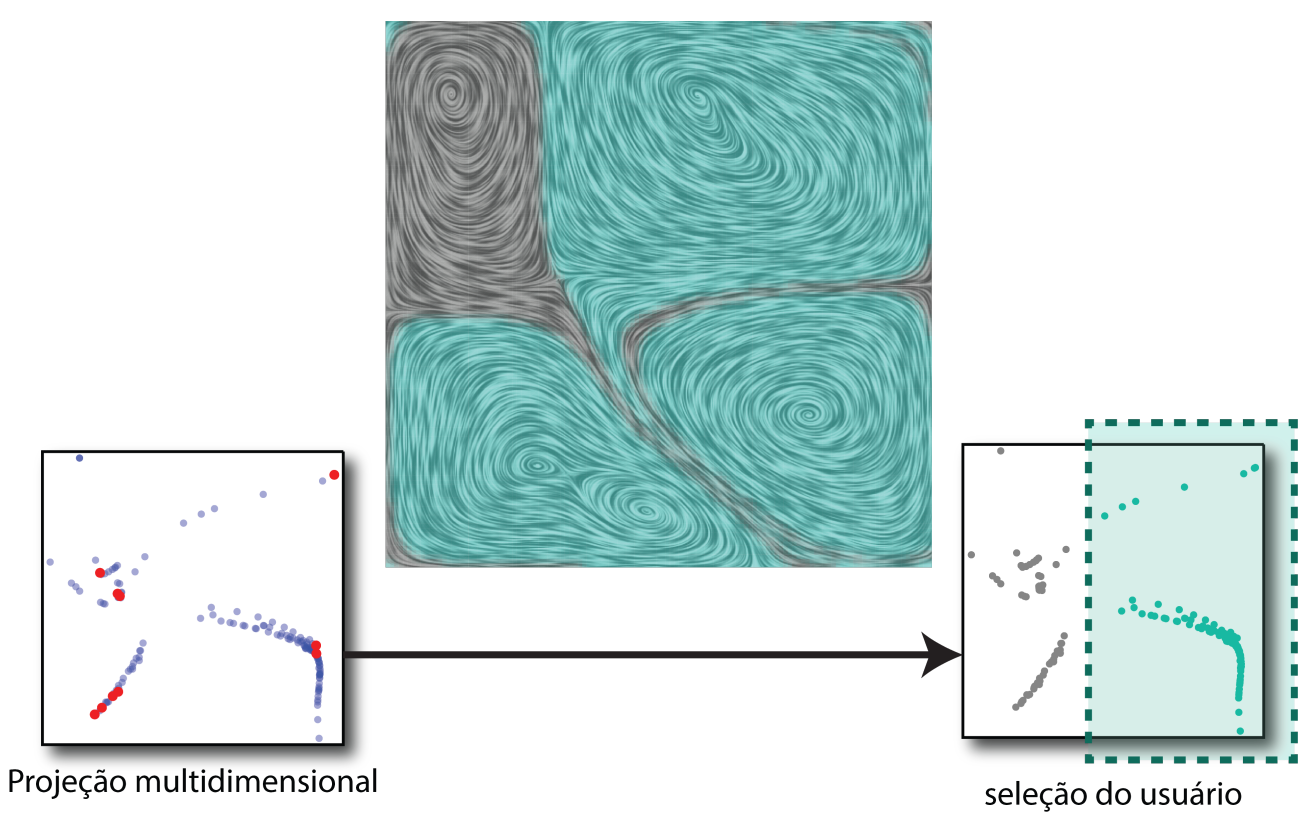

Figura 2.16: Interação com o usuário: seleção.

\subsection{Considerações Finais}

Neste capítulo apresentamos a base teórica em que nos baseamos para construir nosso método, foram descritas as etapas e detalhes que influenciaram as nossas decisões durante o processo de criação. No capítulo a seguir são apresentados os resultados e detalhes de implementação do método. 



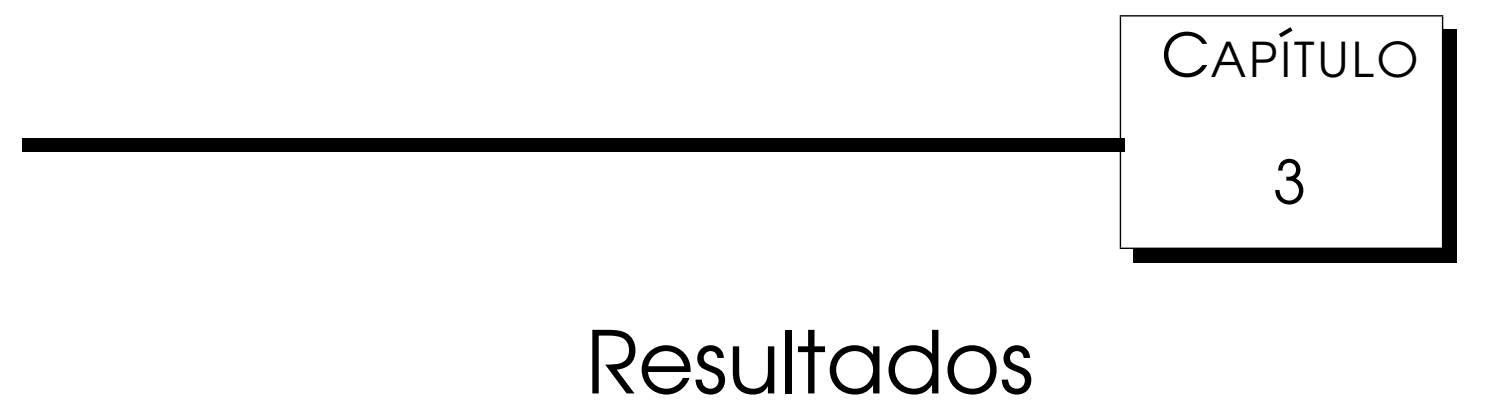

Apresentamos diversos exemplos neste capítulo que demonstram a capacidade do novo método descrito no capítulo 2. Para gerar os exemplos, usamos um passo de tempo $\delta_{t}=0.05$ para integração das streamlines e distribuições de frequência com 10 subintervalos para os conjuntos de dados. Para manter o número de dimensões de nossos dados limitado, escolhemos algumas características, de modo experimental. As características selecionadas foram: magnitude da curvatura, vorticidade absoluta, magnitude da velocidade e divergência. Para cada experimento, salientamos se houve alteração nos parâmetros ou interação com o usuário.

\subsection{Experimentos}

Na primeira etapa desta pesquisa, foram gerados alguns campos vetoriais para testar os resultados em casos simples, e observando os resultados que desejamos, passamos para dados mais complexos. As figura 3.1 e 3.2 demonstram dois destes campos vetoriais artificiais.

\subsubsection{Dois vórtices}

Na figura 3.1 vemos um campo laminar onde foram sobrescritos dois vórtices. É observada segmentação à esquerda, ao lado da projeção e seus agrupamentos à direita. O campo inicial apresentou resultados conforme desejados: 
os vórtices foram separados (em laranja), assim como a região totalmente laminar (em verde) e a região com alguma curvatura (em azul), devido à ação dos vórtices. As características usadas para essa segmentação foram a magnitude da velocidade, magnitude da curvatura e a vorticidade absoluta.
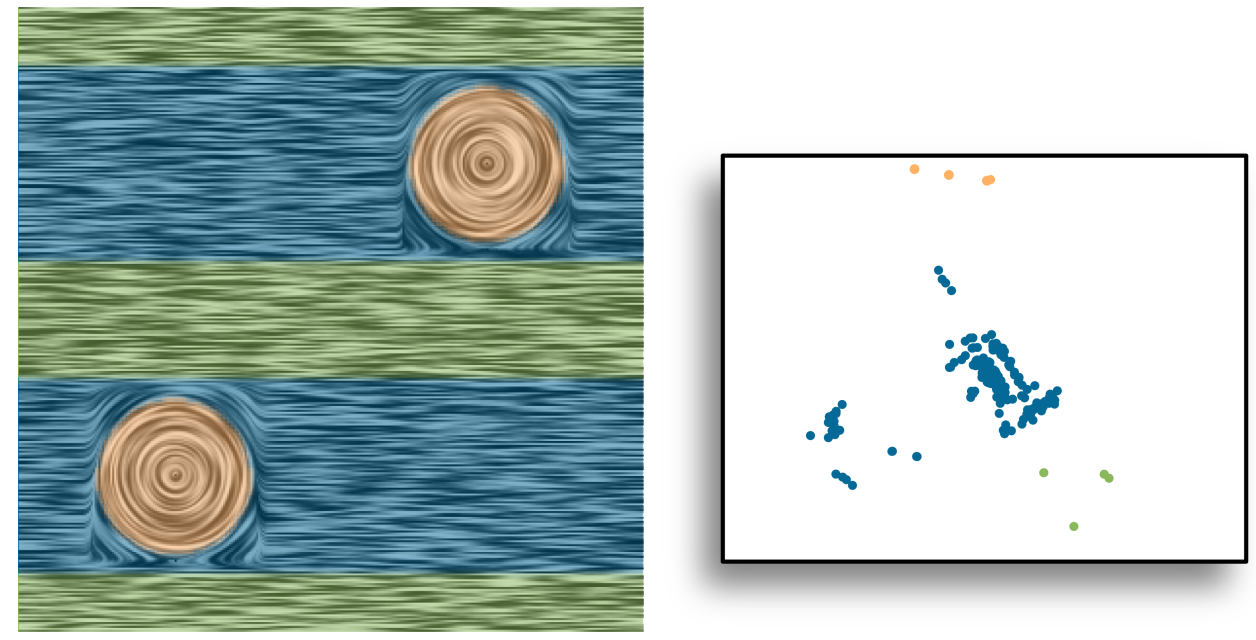

Figura 3.1: Segmentação de campo vetorial artificial: dois vórtices.

\subsection{2 $U=\left(y, x^{2}\right)$}

Na figura 3.2 temos o campo definido como $U=\left(y, x^{2}\right)$, no domínio $[-2 \ldots 2$, $-2 \ldots 2$. Novamente obtemos bons resultados iniciais: separamos uma região que possui um ponto crítico (em verde), assim como uma região de alta curvatura (em azul) e uma região de curvatura baixa (em laranja). Para este experimento, utilizamos apenas magnitude da curvatura e a vorticidade absoluta como características.
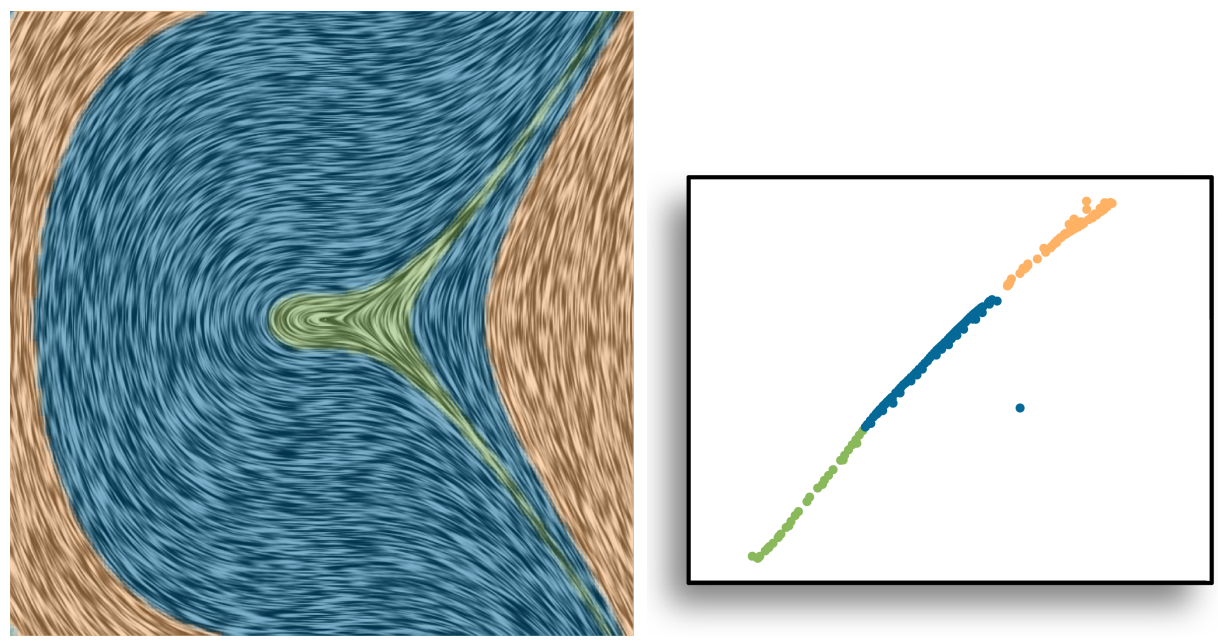

Figura 3.2: Segmentação de campo vetorial artificial: $U=\left(y, x^{2}\right)$. 


\subsubsection{Singularidades}

A figura 3.3 mostra a segmentação de um campo obtido de uma das bibliotecas do software comercial MATLAB [53]. O mesmo campo teve as singularidades classificadas e foi segmentado por Li et al. [26], conforme mostrado na figura 1.2. Observando a classificação de Li na figura 1.2 e a segmentação resultante do nosso método, podemos concluir que conseguimos efetivamente segmentar quase todas as singularidades do campo. A singularidade número 5 não é segmentada, pois o método considera as regiões que a envolvem como regiões de características semelhantes. Neste momento, podemos afirmar que existe a possibilidade de que não tenhamos utilizado características suficientemente boas para a segmentação de todas as singularidades. Além disso, parte dos detalhes da região fina amarela é perdida na suavização.

Para tentar solucionar este problema, poderíamos interagir com os pontos de controle, mudar os agrupamentos manualmente ou testar outras características, mas preferimos não o fazer para ilustrar uma limitação do método. Para essa segmentação foram selecionadas apenas duas características: divergência do campo e a magnitude da curvatura. Apenas neste experimento foi necessário aumentar para 20 o número de subintervalos das distribuições de frequências para obter uma representação mais refinada dos dados.

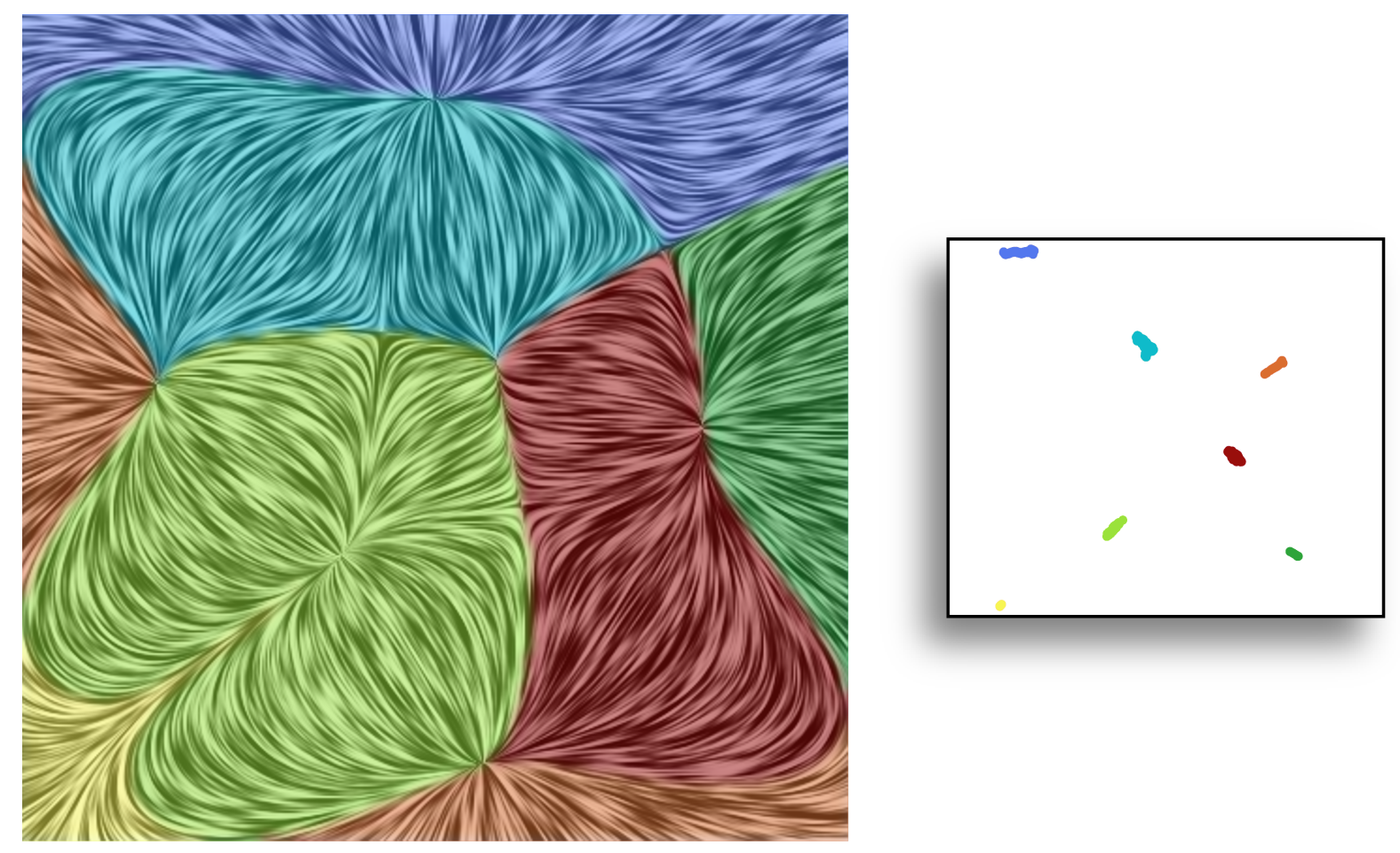

Figura 3.3: Segmentação de campo vetorial: singularidades. 


\subsubsection{Correntes de ar}

Em seguida, segmentamos um corte em um campo vetorial que representa correntes de ar na América do Norte obtido da biblioteca de dados do MATLAB [53]. O resultado é observado na figura 3.4. A segmentação apresenta três vórtices (em verde), dois maiores e um menor entre eles, separados de duas outras regiões (laranja e azul). As regiões laranja e azul são classificadas diferentemente devido à alta diferença na magnitude observada nas mesmas.
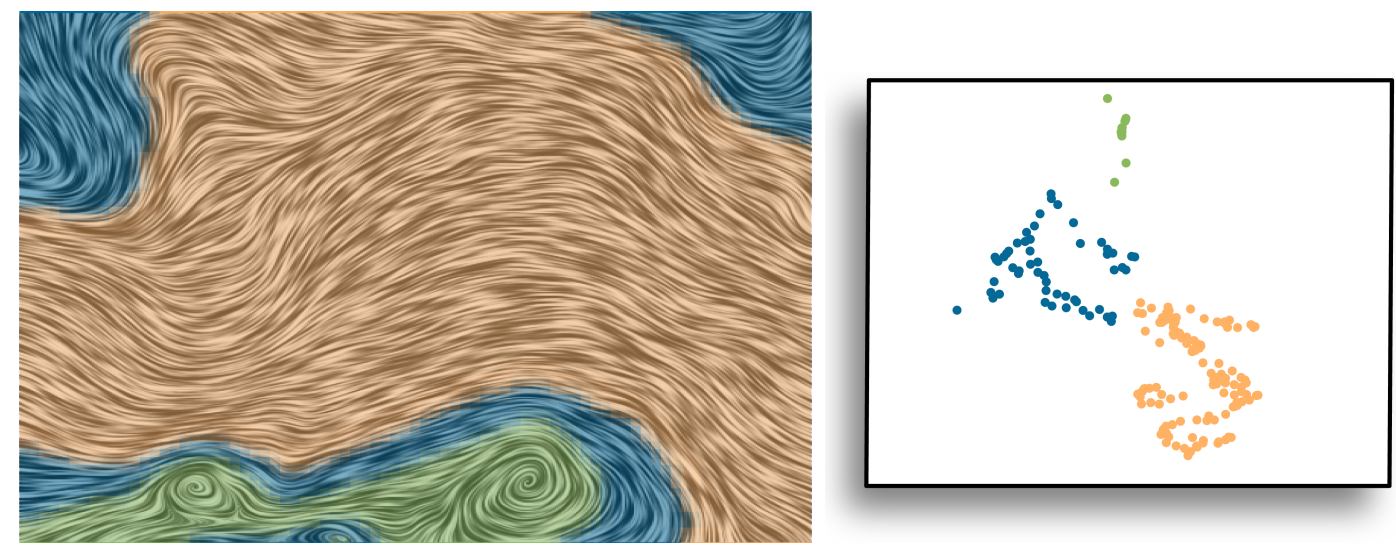

Figura 3.4: Segmentação de campo vetorial: ventos norte americanos.

\subsubsection{Von Kármán}

A segmentação apresentada na figura 3.5 mostra a efetividade de nossa técnica em segmentar vórtices e estruturas de um escoamento em torno de um cilindro. O objetivo era segmentar os vórtices que ocorrem naturalmente nesse tipo de escoamento. A segmentação obtida se assemelha com estradas de Von Kármán, observadas em escoamentos em torno de cilindros. Podemos observar os vórtices com mesmo comportamento destacados, o objetivo da segmentação. Este conjunto de dados foi obtido de simulação feita utilizando o software livre Gerris Flow Solver [1, 54] que resolve equações diferenciais parciais em escoamentos de fluidos.

\subsubsection{PIV}

O experimento seguinte lida com dados de particle image velocimetry (PIV), os quais correspondem a campos vetoriais resultantes de simulações de comportamento turbulento em escoamento com baixo número de Reynolds. Nosso 

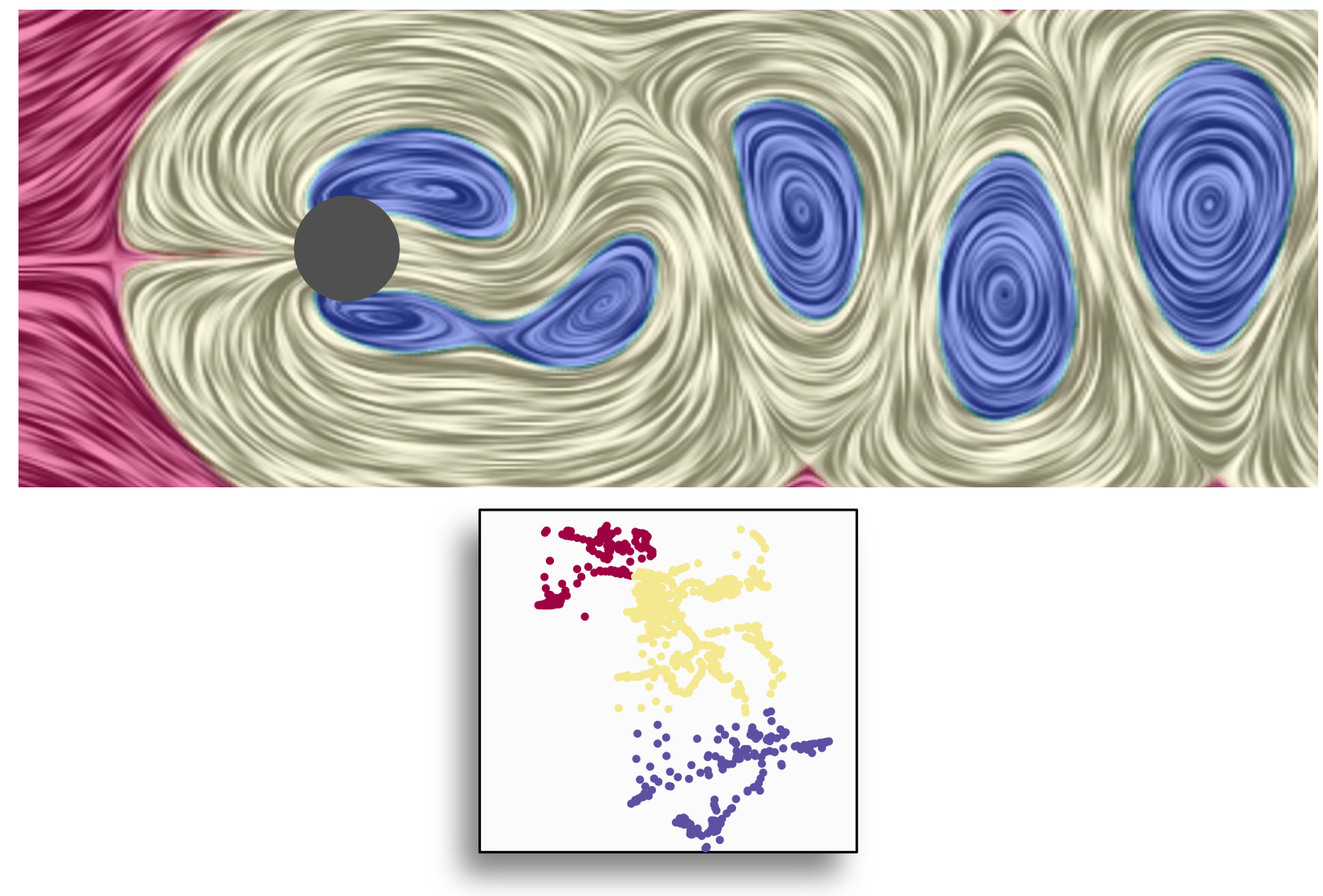

Figura 3.5: Segmentação de um campo vetorial com estrada de Von Kármán.

objetivo é segregar o escoamento laminar e o escoamento turbulento. Escolhemos não usar o divergente do campo nesse caso, já que não adiciona informação relevante. A figura 3.6 mostra os resultados obtidos. Nota-se que as características utilizadas foram capazes de discriminar a região com turbulência mais significativa. Os dados utilizados neste exemplo são públicos e podem ser obtidos em http://ltcf.tam.uiuc.edu/downloads/Data/BL/, e uma análise mais complexa do mesmo é apresentada em [55].

\subsubsection{Interação com usuário: pontos de controle}

No próximo experimento, tiramos proveito da interação com usuário suportada pela LAMP. A figura 3.7 mostra a segmentação do campo vetorial antes e depois do usuário mover os pontos de controle (em vermelho) utilizando o mouse. Na parte superior, vemos a segmentação antes da interação e inferior depois da interação. Nota-se que a segmentação muda significativamente depois do reposicionamento dos pontos de controle no espaço visual, ilustrando a flexibilidade permitida pela nossa metodologia para intervir interativamente 


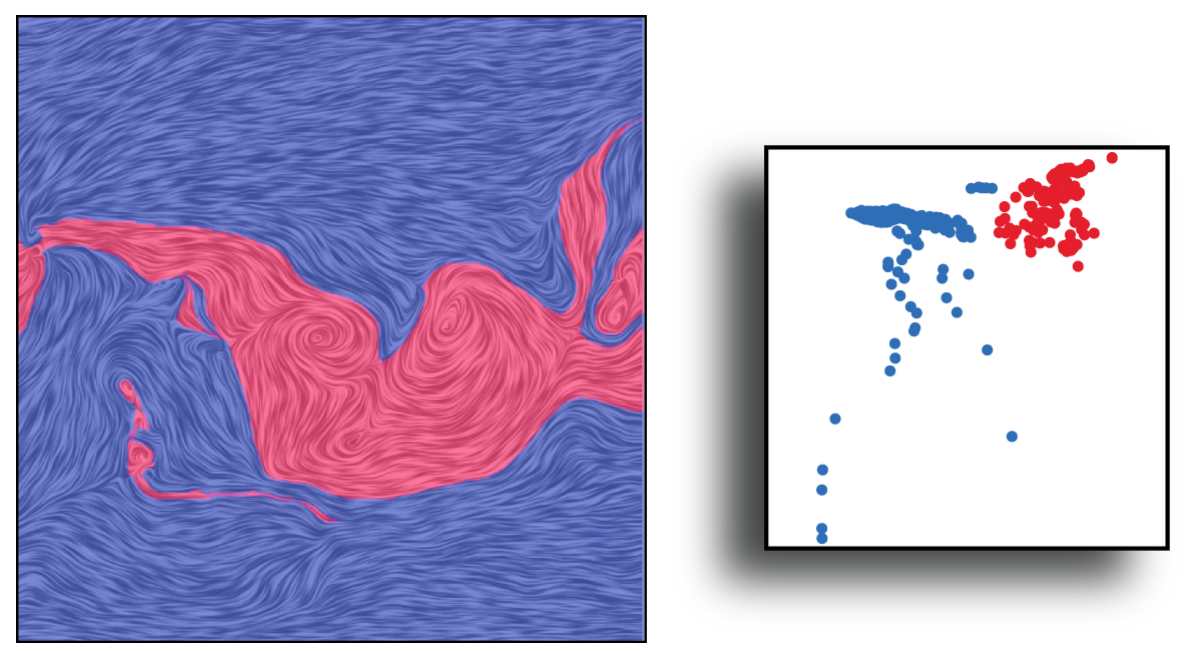

Figura 3.6: Resultado da segmentação de dados PIV.

no processo de segmentação. Novamente os dados foram obtidos utilizando o Gerris Flow Solver.
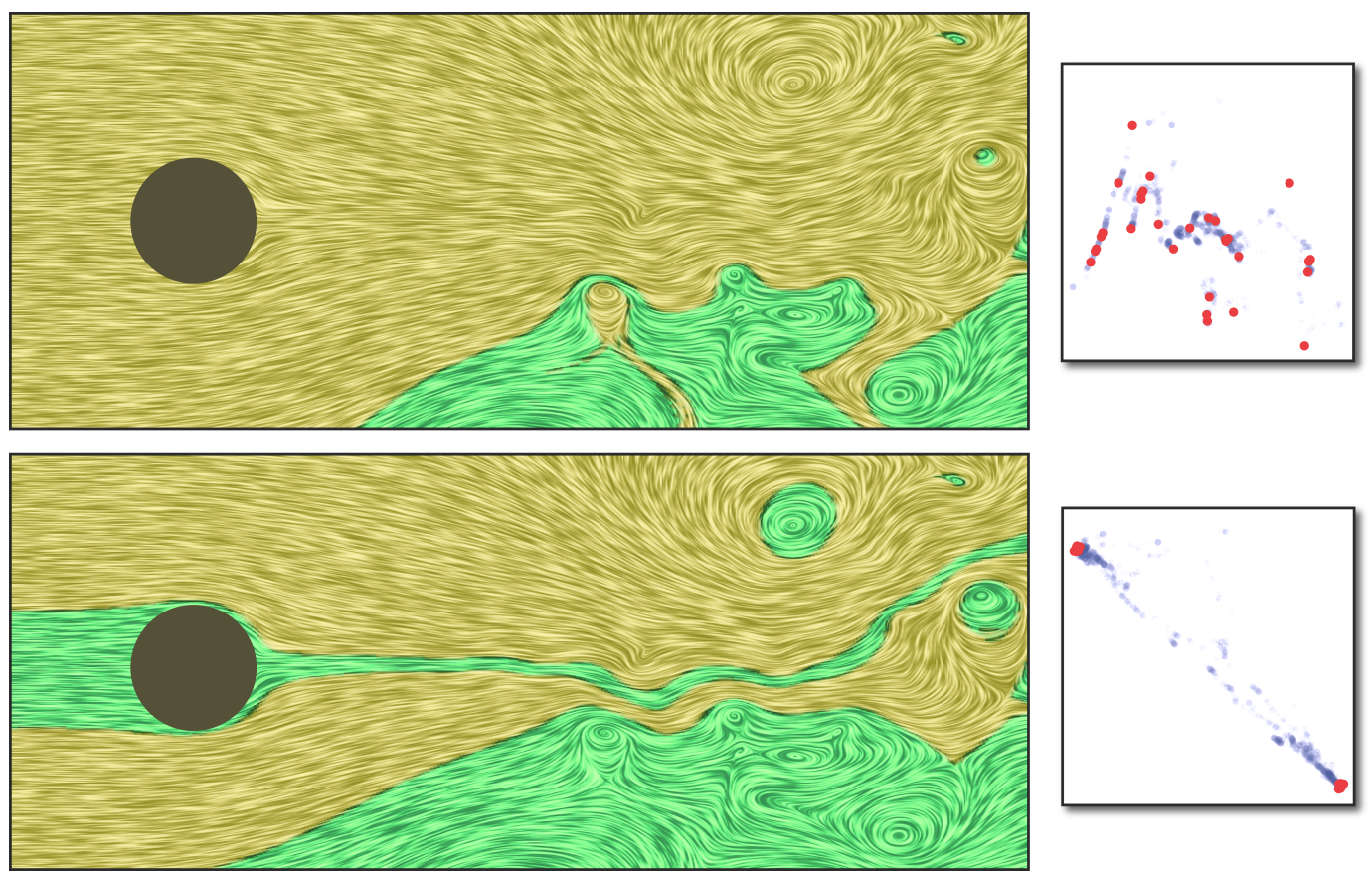

Figura 3.7: Resultado aprimorado pela interação com os pontos de controle.

\subsubsection{Interação com usuário: número de agrupamentos}

O último experimento mostra outra interação, onde o usuário explora o número de agrupamentos da visualização. Na figura 3.8, o usuário executa o algoritmo de agrupamento com dois grupos e, em seguida, vemos o resultado quando cinco grupos são fornecidos como parâmetro. Observamos que, 
devido ao algoritmo hierárquico, os agrupamentos são subdivididos criando novos agrupamentos e assim revelando novas estruturas como os vórtices (em laranja e vermelho) vistos no interior das estruturas.

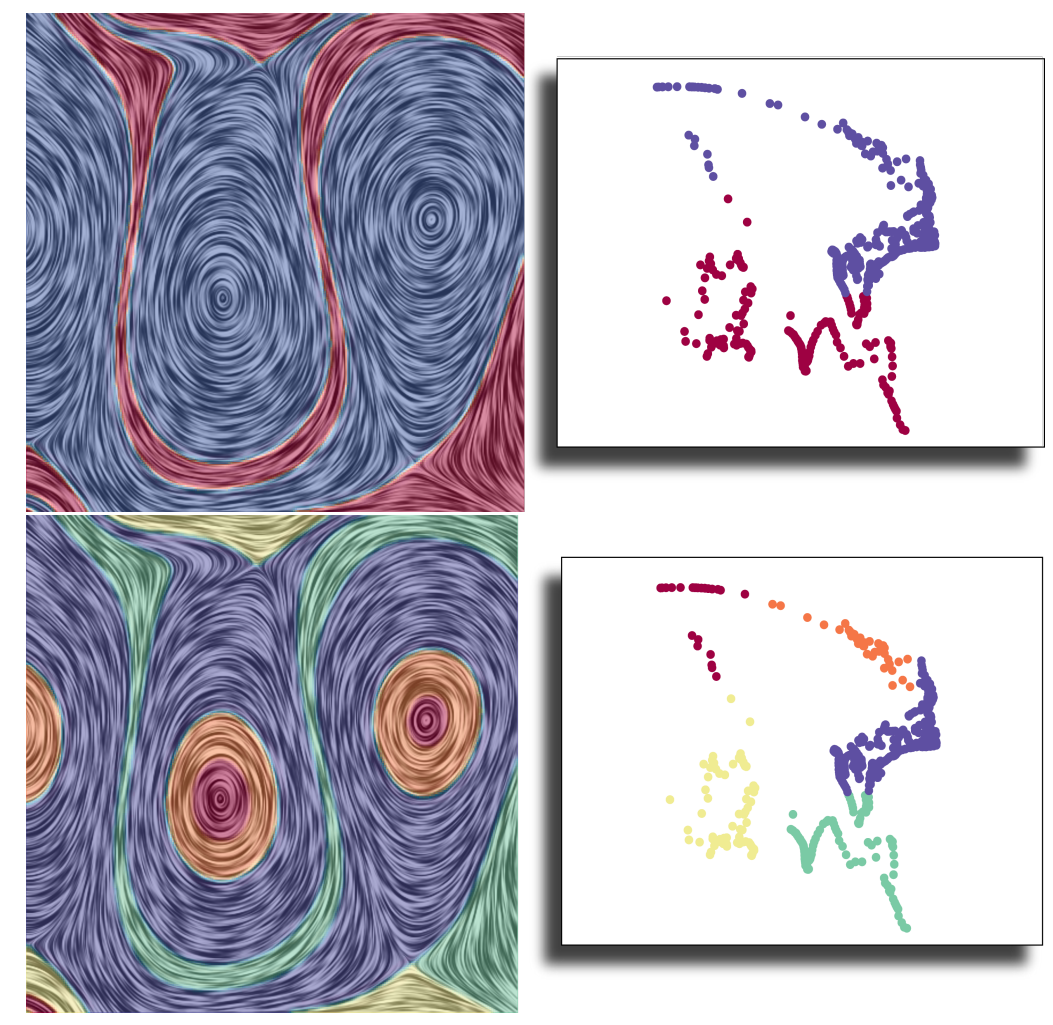

Figura 3.8: Interação com usuário: variação do número de agrupamentos.

\subsection{Comparações}

Com o objetivo de verificar a qualidade da segmentação produzida pelo nosso método, fazemos a sua comparação com o proposto por Daniels et al. [16] o qual também constrói vetores de características, porém extraídos de propriedades na vizinhança de cada célula da malha, por exemplo, usando $k$ nearest neighbors (KNN). Mais precisamente, usamos a curvatura, divergência, magnitude da velocidade, a intensidade e direção de rotação dos vetores em cada célula da malha, concatenando então essas propriedades e gerando o vetor de características no espaço de dimensão alta.

Na figura 3.9, a segmentação é realizada em um campo vetorial de simulação de fumaça. A imagem à esquerda mostra o resultado da segmentação com características extraídas como proposto por Daniels [16] usando os 30 vizinhos mais próximos como amostras. A imagem à direita mostra o resultado obtido 
pelo nosso método. Projeções e agrupamentos no espaço visual são mostrados ao lado. Nota-se que a qualidade da segmentação produzida usando a abordagem de vizinhança proposta por Daniels é pior que a produzida pelo nosso método. É importante relatar que, em seu artigo original, Daniels usou um número maior de características, porém tentamos mostrar aqui que, em contraste com nossa abordagem, o método descrito por Daniels não funciona corretamente com um número reduzido de características.
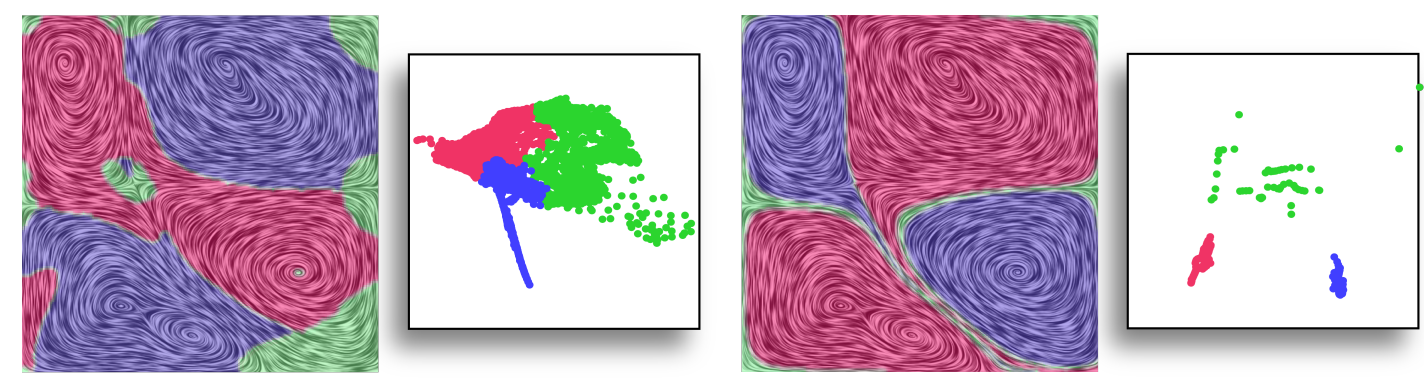

Figura 3.9: Comparação com método baseado em espaço de dimensão alta.

A figura 3.10 compara nossa abordagem contra o método Edge Maps proposto por Bahtia et al. [31] usando um campo vetorial sintético. Edge Maps depende das propriedades topológicas do campo vetorial para realizar a segmentação e é considerado o estado da arte no contexto de segmentação topológica de campos vetoriais. Podemos perceber que nossa abordagem, mais simples de implementar, atinge os mesmos resultados que Edge Maps. Em contraste com Edge Maps, nosso método não possui garantias teóricas para afirmar que as segmentações geradas sempre acompanham o comportamento do campo.
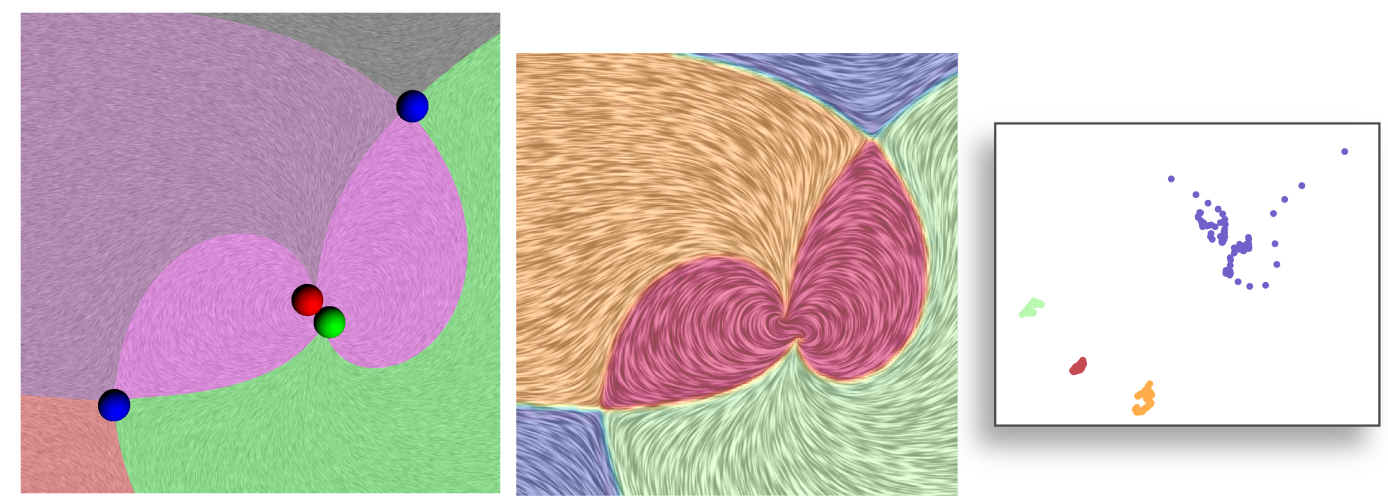

Figura 3.10: Comparação entre o método Edge Maps [30] (esquerda) e o nosso método acompanhado da projeção (direita). 


\subsection{Extensão para 3D}

A dificuldade em implementar a extensão da técnica desenvolvida para o 3D não se encontra na extração de características ou no processo de segmentação, mas sim em demonstrar de forma intuitiva ao usuário as regiões segmentadas, que precisou ser reformulada. Colorização das regiões segmentadas em 3D geraria oclusão demasiada tornando impossível uma visualização de qualidade. A decisão tomada foi a de usar superfícies que delimitam a região de contato entre dois agrupamentos e para auxiliar na compreensão do escoamento são também mostradas streamlines com a coloração dada pelos seus respectivos agrupamentos.

Resultados em 3D são demonstrados nas figuras 3.11 e 3.12. Novamente utilizamos o campo vetorial que representa correntes de ar na América do Norte obtido da biblioteca de dados do MATLAB [53]. A figura 3.11 apresenta um subvolume onde vemos claramente vórtices e uma região mais comportada. A superfície traçada separa bem as duas regiões de comportamentos distintos. Já na figura 3.12, utiliza-se todo o conjunto de dados e novamente separamos o campo vetorial em dois agrupamentos, um com comportamento laminar e outro rotacional. Os resultados condizem com o desejado e as características utilizadas nesse processo foram as mesmas apresentadas anteriormente, porém em 3D foi implementada também torção conforme definida no capítulo 2.

A estratégia adotada é simples e eficaz nos casos apresentados, porém, quando se define muitos agrupamentos a sobreposição de várias superfícies também causaria oclusão. Para esses casos, o usuário pode selecionar os agrupamentos que deseja visualizar e remover agrupamentos que não têm interesse. A abordagem usada é suficiente para mostrar que os resultados da técnica apresentada, estendida automaticamente para 3D, é efetiva em separar grupos significativos nos exemplos apresentados, porém novos tipos de estratégias para visualizar a segmentação de grupos em 3D devem ser estudados no futuro.

\subsection{Análise de esforço computacional}

O desempenho computacional é apresentado na tabela 3.1. Medimos tempos em um Intel Core 2 Duo de $2.53 \mathrm{GHz}$ com 2GB de RAM. MATLAB foi usado na implementação do método proposto em 2D e C++ [56] para a versão 3D. 
Observando a tabela 3.1 podemos perceber que o tempo de execução do método é influenciado tanto pelo tamanho da malha como o número de streamlines utilizadas. Conforme observado na linha 2 e 3 da tabela, uma malha maior pôde ser processada com tempo de execução menor que o de uma malha maior, devido ao uso poucas streamlines. Campos com várias singularidades como o visto na linha 3 da tabela tendem a necessitar de mais curvas para serem cobertos, justificando o número de streamlines utilizadas. Os campos vetoriais que conseguimos cobrir com um número menor de streamlines serão processados mais rapidamente que campos que precisem de mais curvas. $\mathrm{O}$ gargalo dos métodos que utilizam projeção como ferramenta, geralmente se encontra no alto esforço para se projetar grandes quantidades de pontos. Ao utilizar streamlines como amostras, retiramos parte da influência do tamanho da malha sobre o esforço computacional. Porém, o custo de se computar essas curvas é considerável e este custo é agravado quando estamos em 3D, conforme visto nas últimas duas linhas da tabela.

Os tempos das últimas duas linhas não devem ser comparados com as superiores pois foram implementadas em plataformas diferentes, embora executadas na mesma máquina. Além disso, nenhuma otimização quanto a ganho de tempo foi desenvolvida, embora possamos afirmar que o método desenvolvido tem muito a ganhar com a utilização de paralelismo.

Devemos agradecer também pelo código da LAMP [47] em C, descrito anteriormente na seção 2.4, utilizado na versão 3D do método, implementado por Paulo Joia, também membro do Grupo de Processamento Visual e Geométrico (GPVG) do Instituto de Ciências Matemáticas e de Computação (ICMC-USP). Este código está disponível publicamente em https://code.google.com/p/ projection-analyzer/.

\subsection{Considerações Finais}

Neste capítulo foram apresentados os resultados do novo método para vários conjuntos de dados, onde os resultados se mostraram efetivos. Demonstramos como a interação com o usuário pode beneficiar a qualidade dos resultados. Também mostramos limitações do método em 2D e 3D. Fizemos comparações, mostrando que o método desenvolvido, mesmo não garantindo a resposta ótima, pode comportar-se de modo semelhante a métodos considerados estado da arte. 
Tabela 3.1: Tempos computacionais (em segundos).

\begin{tabular}{c|c|c|c|c|c} 
& Experimento & Seção & Tamanho da malha & \# Streamlines & Tempo \\
\hline \hline 1 & Dois vórtices & 3.1 .1 & $161 \times 161$ & 415 & 10.66 \\
2 & $U=\left(y, x^{2}\right)$ & 3.1 .2 & $160 \times 160$ & 276 & 9.97 \\
3 & Singularidades & 3.1 .3 & $120 \times 120$ & 731 & 28.80 \\
4 & Correntes de ar & 3.1 .4 & $103 \times 120$ & 301 & 8.19 \\
5 & Von Kármán & 3.1 .5 & $197 \times 436$ & 1117 & 804.40 \\
6 & PIV & 3.1 .6 & $240 \times 240$ & 1135 & 409.96 \\
7 & Pontos de controle & 3.1 .7 & $316 \times 241$ & 978 & 62.52 \\
8 & Agrupamentos & 3.1 .8 & $144 \times 144$ & 334 & 12.47 \\
9 & Comparação 1 & 3.2 & $189 \times 189$ & 247 & 29.03 \\
10 & Comparação 2 & 3.2 & $175 \times 175$ & 702 & 49.90 \\
\hline 11 & 3D 1 & 3.3 & $16 \times 14 \times 8$ & 141 & 57.04 \\
12 & 3D 2 & 3.3 & $35 \times 41 \times 15$ & 1244 & 91.22
\end{tabular}



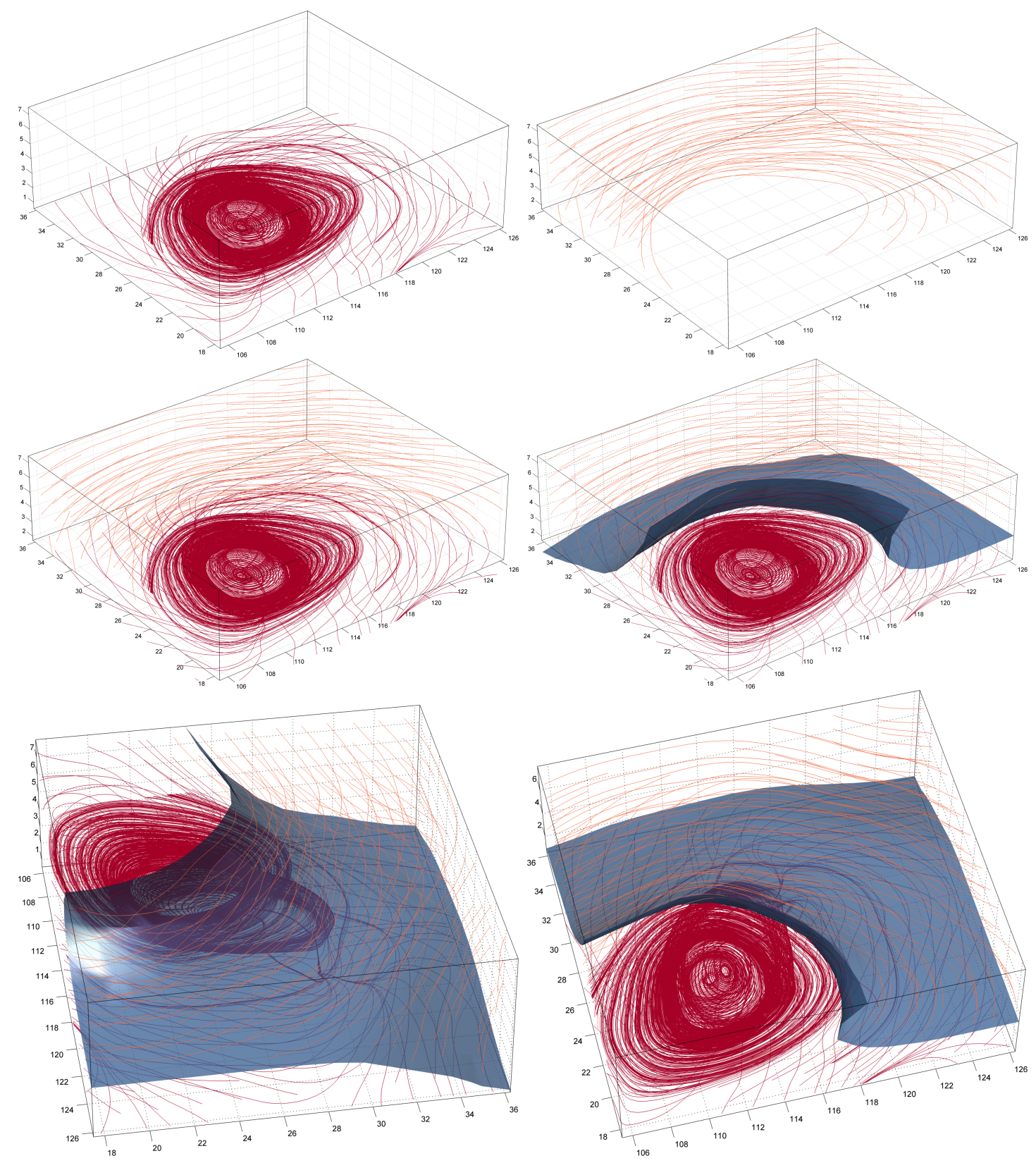

Figura 3.11: Segmentação de campo vetorial 3D: corte do campo. 

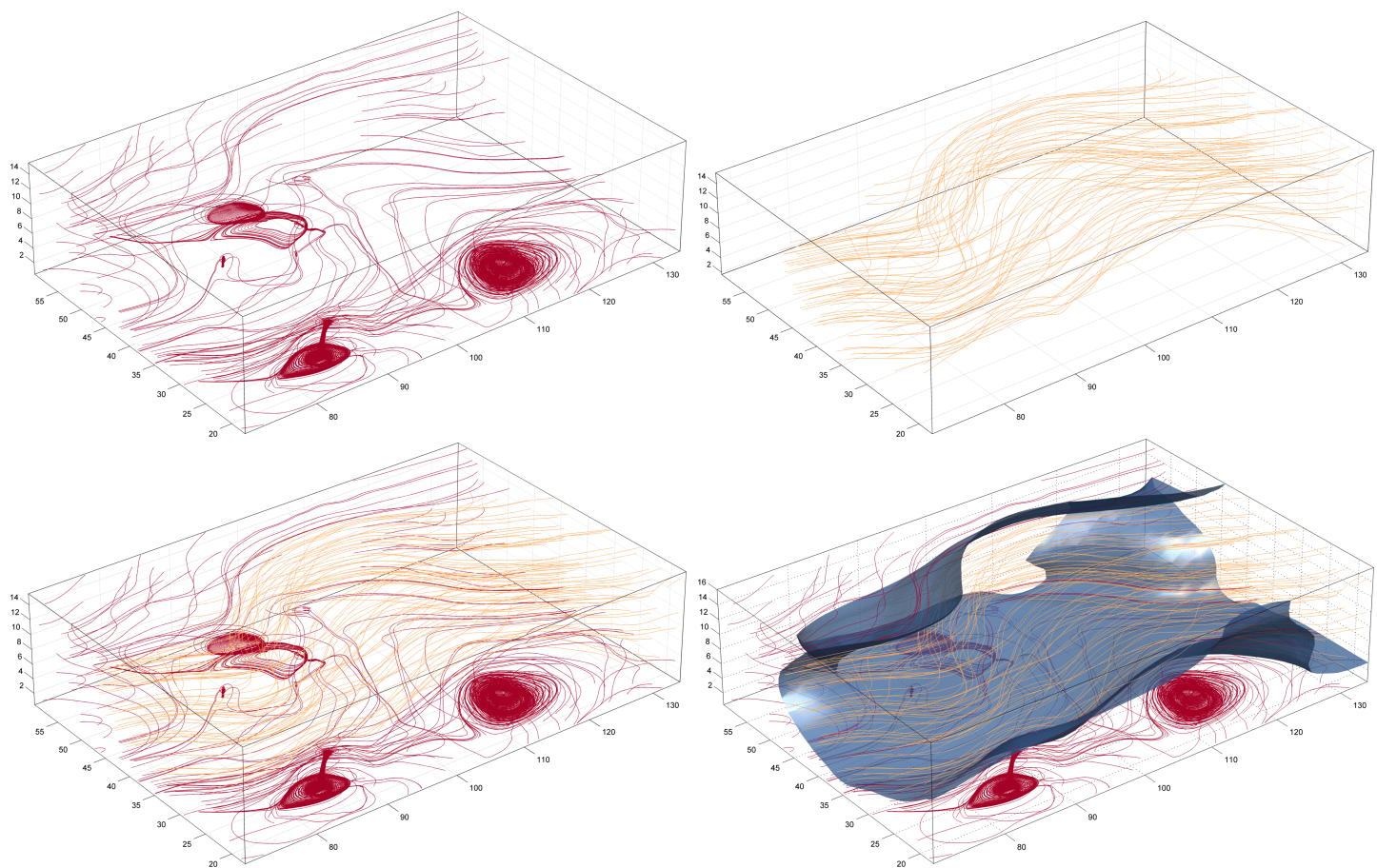

Figura 3.12: Segmentação de campo vetorial 3D: campo completo 



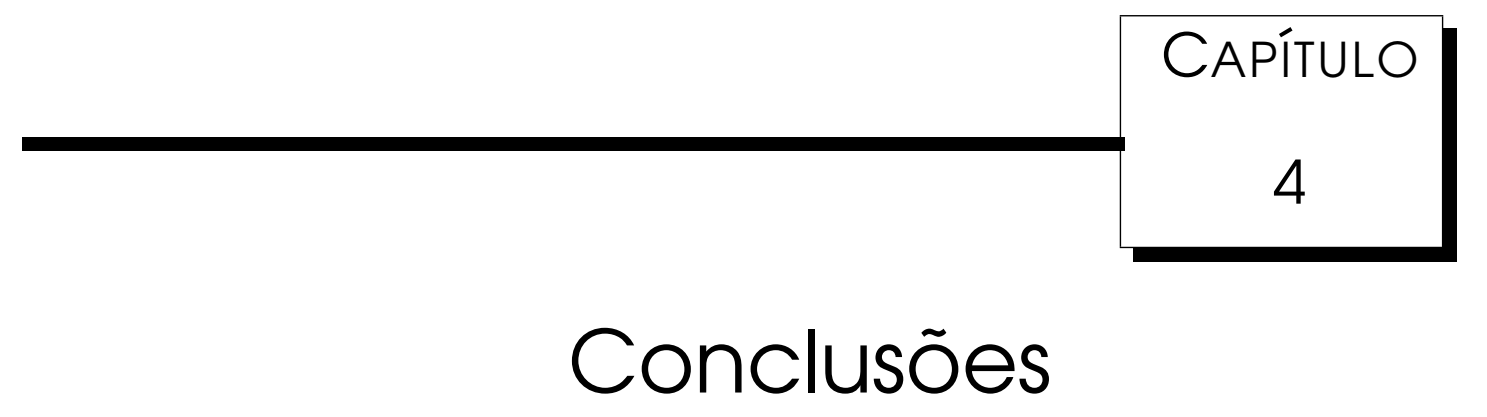

Durante esta pesquisa, revisamos o que foi desenvolvido na área de visualização de campos vetoriais, com foco nos métodos de segmentação. Observando que nenhum trabalho existente cobria todos os nossos objetivos, o alvo dos estudos passou para a criação de uma nova técnica. Pelos resultados apresentados podemos observar que nosso método consegue lidar com uma grande variedade de dados. É também flexível, pois permite que o usuário inclua seu conhecimento para melhorar os resultados da segmentação.

Usamos streamlines como um mecanismo de amostragem, e as representamos no espaço de características como distribuições de frequências de suas características locais, uma das principais contribuições deste trabalho. O uso desses vetores remove o gargalo de se computar grandes malhas de campos vetoriais.

Outras características, além das abordadas, como densidade e pressão, poderiam ser usadas, quando disponíveis, sem mudar o pipeline proposto.

As comparações mostram que nossa abordagem pode capturar estruturas de escoamentos, gerando resultados similares a métodos topológicos de alta precisão.

Nosso método pode produzir artefatos em alguns casos, gerando agrupamentos não bem definidos. A falta de garantia teórica para afirmar que as segmentações geradas sempre acompanham o comportamento do campo é uma das limitações da abordagem atual. 
Muitos trabalhos futuros foram traçados. Melhorias em desempenho e na visualização de campos vetoriais em 3D são opções obvias. Futuramente, pode-se aprimorar os resultados utilizando características topológicas do campo. Ainda há muito o que melhorar no quesito desempenho, a técnica foi implementada e executada sem a preocupação com a otimização do processo. A abordagem usada para o problema é altamente paralelizável, o que pode ser explorado.

Além de melhorias, a técnica desenvolvida pode ser usada na comparação entre vários campos vetoriais, utilizando o mesmo espaço de projeção. Atualmente, a técnica pode realizar essa tarefa apenas modificando a entrada para que se aceite mais de um campo vetorial. Outra abordagem a se considerar é o processamento de campos variantes no tempo, onde se pode aplicar técnicas de detecção de novidades para encontrar estruturas novas que se formam durante os escoamentos. Outros estudos futuros incluem detecção de ondas de choque, aplicação em campos vetoriais sobre malhas e filtragem de objetos geométricos que ocasionam em oclusão em três dimensões. 


\section{Referências Bibliográficas}

[1] POPINET, S. Gerris: a tree-based adaptive solver for the incompressible euler equations in complex geometries. J. Comput. Phys., Academic Press Professional, Inc., San Diego, CA, USA, v. 190, n. 2, p. 572-600, setembro 2003. ISSN 0021-9991. Disponivel em: <http://dx.doi.org/10.1016/ S0021-9991(03)00298-5>.

[2] F., A. C.; TOMÉ, M.; CÉSAR, C.; MCKEE, S.; CUMINATO, J. Freeflow: an integrated simulation system for three-dimensional free surface flows. Computing and Visualization in Science, Springer, v. 2, n. 4, p. 199-210, 2000 .

[3] ADRIAN, R.; WESTERWEEL, J. Particle Image Velocimetry. Cambridge University Press, 2010. (Cambridge Aerospace Series). ISBN 9780521440080. Disponivel em: <http://books.google.com.br/books? $i d=j b D 12-y H b \circ o C>$.

[4] SIEDLER, G.; GRIFFIES, S.; GOULD, J.; CHURCH, J. Ocean Circulation and Climate: Observing and Modelling the Global Ocean. Elsevier Science, 2001. (International Geophysics). ISBN 9780080491974. Disponível em: <http://books.google.com.br/books?id=5a21rUcjS-IC>.

[5] POST, F. H.; VROLIJK, B.; HAUSER, H.; LARAMEE, R. S.; DOLEISCH, $\mathrm{H}$. The state of the art in flow visualisation: Feature extraction and tracking. 2003. Disponivel em: <http://citeseerx.ist.psu.edu/viewdoc/ summary?doi=10.1.1.4.1928>.

[6] HELMAN, J.; HESSELINK, L. Visualizing vector field topology in fluid flows. Computer Graphics and Applications, IEEE, v. 11, n. 3, p. 36 -46, maio 1991. ISSN 0272-1716. 
[7] THEISEL, H.; SEIDEL, H.-P. Feature flow fields. In: Proceedings of the symposium on Data visualisation 2003. Aire-la-Ville, Switzerland, Switzerland: Eurographics Association, 2003. (VISSYM '03), p. 141-148. ISBN 1-58113698-6. Disponivel em: <http://dl.acm.org/citation. cfm?id=769922. 769938>.

[8] THEISEL, H.; SAHNER, J.; WEINKAUF, T.; HEGE, H.-C.; SEIDEL, H.-P. Extraction of parallel vector surfaces in 3D time-dependent fields and application to vortex core line tracking. In: Proc. IEEE Visualization 2005. Minneapolis, U.S.A.: , 2005. p. 631-638. Disponivel em: <http://tinoweinkauf. net/publications/abstheisel05b.html>.

[9] NASCIMENTO, R.; PAIXAO, J.; LOPES, H.; LEWINER, T. Topology aware vector field denoising. In: Proceedings of the 2010 23rd SIBGRAPI Conference on Graphics, Patterns and Images. Washington, DC, USA: IEEE Computer Society, 2010. (SIBGRAPI '10), p. 103-109. ISBN 978-0-7695-4230-0. Disponivel em: <http://dx.doi.org/10.1109/SIBGRAPI.2010.22>.

[10] LARAMEE, R.; HAUSER, H.; ZHAO, L.; POST, F. Topology-based flow visualization, the state of the art. p. 1-18, 2007. Disponivel em: <http: //www.springerlink.com/index/H7182744694M3462.pdf>.

[11] POBITZER, A.; PEIKERT, R.; FUCHS, R.; SCHINDLER, B.; KUHN, A.; THEISEL, H.; MATKOVIĆ, K.; HAUSER, H. The State of the Art in TopologyBased Visualization of Unsteady Flow. Computer Graphics Forum, v. 30, n. 6, p. 1789-1811, setembro 2011. ISSN 01677055. Disponível em: <http:// doi.wiley.com/10.1111/j.1467-8659.2011.01901.x>.

[12] CABRAL, B.; LEEDOM, L. C. Imaging vector fields using line integral convolution. In: Proceedings of the 20th annual conference on Computer graphics and interactive techniques. New York, NY, USA: ACM, 1993. (SIGGRAPH '93), p. 263-270. ISBN 0-89791-601-8. Disponivel em: <http: //doi.acm.org/10.1145/166117.166151>.

[13] REZK-SALAMA, C.; HASTREITER, P.; TEITZEL, C.; ERTL, T. Interactive exploration of volume line integral convolution based on 3d-texture mapping. In: Proceedings of the conference on Visualization '99: celebrating ten years. Los Alamitos, CA, USA: IEEE Computer Society Press, 1999. (VIS '99), p. 233-240. ISBN 0-7803-5897-X. Disponivel em: <http://dl.acm. org/citation. cfm?id=319351.319379>. 
[14] LI, G.-S.; BORDOLOI, U.; SHEN, H.-W. Chameleon: An interactive texture-based rendering framework for visualizing three-dimensional vector fields. In: TURK, G.; WIJK, J. J. van; II, R. J. M. (Ed.). IEEE Visualization. IEEE Computer Society, 2003. p. 241-248. ISBN 0-7803-8120-3. Disponivel em: <http://dblp.uni-trier.de/db/conf/visualization/ visualization2003.html\#LiBS03>.

[15] POBITZER, A.; TUTKUN, M.; ANDREASSEN, O.; FUCHS, R.; PEIKERT, R.; HAUSER, H. Energy-scale Aware Feature Extraction for Flow Visualization. Computer Graphics Forum, v. 30, n. 3, p. 771-780, junho 2011. ISSN 01677055. Disponivel em: <http://doi.wiley.com/10.1111/j. $1467-8659.2011 .01926 . x>$.

[16] DANIELS, J.; ANDERSON, E.; NONATO, L.; SILVA, C. Interactive vector field feature identification. Visualization and Computer Graphics, IEEE Transactions on, v. 16, n. 6, p. 1560 -1568, novembro-dezembro 2010. ISSN 1077-2626.

[17] RÖSSL, C.; THEISEL, H. Streamline embedding for 3D vector field exploration. IEEE transactions on visualization and computer graphics, v. 18, n. 3, p. 407-20, março 2012. ISSN 1941-0506. Disponivel em: <http: //www.ncbi.nlm.nih.gov/pubmed/21519106>.

[18] MCLOUGHLIN, T.; JONES, M. W.; LARAMEE, R. S.; MALKI, R.; MASTERS, I.; HANSEN, C. D. Similarity measures for enhancing interactive streamline seeding. IEEE Transactions on Visualization and Computer Graphics, p. 1-1, 2012. ISSN 1077-2626. Disponivel em: <http://ieeexplore. ieee.org/lpdocs/epic03/wrapper.htm?arnumber=6231627>.

[19] MAHROUS, K.; BENNETT, J.; SCHEUERMANN, G.; HAMANN, B.; JOY, K. I. Topological segmentation in three-dimensional vector fields. Visualization and Computer Graphics, IEEE Transactions on, IEEE, v. 10, n. 2, p. 198-205, 2004.

[20] MAX, N.; BECKER, B.; CRAWFIS, R. Flow volumes for interactive vector field visualization. In: Proceedings of the 4th conference on Visualization '93. Washington, DC, USA: IEEE Computer Society, 1993. (VIS '93), p. 19-24. ISBN 0-8186-3940-7. Disponivel em: <http://dl.acm.org/ citation.cfm?id=949845.949854>. 
[21] WEINKAUF, T.; THEISEL, H. Curvature measures of $3 d$ vector fields and their applications. Journal of WSCG, v. 10, n. 2, p. 507-514, 2002.

[22] PEIKERT, R.; ROTH, M. The "parallel vectors" operator: a vector field visualization primitive. In: Proceedings of the conference on Visualization '99: celebrating ten years. Los Alamitos, CA, USA: IEEE Computer Society Press, 1999. (VIS '99), p. 263-270. ISBN 0-7803-5897-X. Disponível em: <http://dl.acm.org/citation.cfm?id=319351.319420>.

[23] MARCHESIN, S.; CHEN, C.-K.; HO, C.; MA, K.-L. View-dependent streamlines for 3d vector fields. Visualization and Computer Graphics, IEEE Transactions on, v. 16, n. 6, p. 1578 -1586, novembro-dezembro 2010. ISSN 1077-2626.

[24] WEI, J.; WANG, C.; YU, H.; MA, K.-L. A sketch-based interface for classifying and visualizing vector fields. In: PacificVis. IEEE, 2010. p. 129-136. Disponível em: <http://dblp.uni-trier.de/db/conf/apvis/ pacificvis2010.html\#WeiWYM10>.

[25] EDMUNDS, M.; LARAMEE, R. S.; CHEN, G.; MAX, N.; ZHANG, E.; WARE, C. Surface-based flow visualization. Computers \& Graphics, Elsevier, 2012.

[26] LI, H.; CHEN, W.; SHEN, I.-F. Segmentation of discrete vector fields. IEEE Transactions on Visualization and Computer Graphics, IEEE Educational Activities Department, Piscataway, NJ, USA, v. 12, n. 3, p. 289-300, maio 2006. ISSN 1077-2626. Disponível em: <http://dx.doi.org/10.1109/ TVCG. $2006.54>$.

[27] PAUlOVICH, F.; NONATO, L.; MINGHIM, R.; LEVKOWITZ, H. Least square projection: A fast high-precision multidimensional projection technique and its application to document mapping. Visualization and Computer Graphics, IEEE Transactions on, v. 14, n. 3, p. 564 -575, maio-junho 2008. ISSN 1077-2626.

[28] JEONG, J.; HUSSAIN, F. On the identification of a vortex. Journal of Fluid Mechanics, 1995. Disponivel em: <http://journals.cambridge. org/production/action/cjoGetFulltext?fulltextid=353420>.

[29] KUHN, A.; LEHMANN, D.; GASTSTEIGER, R.; NEUGEBAUER, M.; PREIM, B.; THEISEL, H. A clustering-based visualization technique to emphasize meaningful regions of vector fields. In: Vision, Modeling, and Visualization. 2011. p. 191-198. 
[30] BHATIA, H.; JADHAV, S.; PASCUCCI, V.; CHEN, G.; LEVINE, J. A.; NONATO, L. G.; BREMER, P.-T. Edge maps: Representing flow with bounded error. In: IEEE PacificVis 2011. 2011. p. 75-82.

[31] BHATIA, H.; JADHAV, S.; PASCUCCI, V.; CHEN, G.; LEVINE, J. A.; NONATO, L. G.; BREMER, P.-T. Flow visualization with quantified spatial and temporal errors using edge maps. IEEE Trans. Vis. Comput. Graph., v. 18, n. 9, p. 1383-1396, 2012.

[32] HUTTENLOCHER, D. P.; KLANDERMAN, G. A.; RUCKLIDGE, W. J. Comparing images using the hausdorff distance. Pattern Analysis and Machine Intelligence, IEEE Transactions on, IEEE, v. 15, n. 9, p. 850-863, 1993.

[33] COX, T. F.; COX, M. A. Multidimensional scaling. : CRC Press, 2010.

[34] KUNDU, P.; COHEN, I. Fluid Mechanics. Academic Press, 2002. (Referex Engineering). ISBN 9780121782511. Disponivel em: <http://books . google.com.br/books? id=VG992gAACAAJ >.

[35] CURRIE, I. Fundamental Méchanics of Fluids. Marcel Dekker, 2003. (Mechanical Engineering). ISBN 9780824708863. Disponivel em: <http: //books.google.com.br/books?id=3cqfjZ5_6xYC>.

[36] WHITE, F. Fluid Mechanics. McGraw-Hill, 2003. (McGraw-Hill Series in Mechanical Engineering). ISBN 9780072402179. Disponível em: <http: / /books.google.com.br/books?id=1DYtptq30C4C>.

[37] CHAPRA, S. C.; CANALE, R. Numerical methods for engineers. : McGrawHill, Inc., 2005.

[38] KAPLAN, W. Advanced calculus. : Addison-Wesley Reading, MA, 1952.

[39] VATTER, V. Green's Theorem for Circulation and Curl. 2010. Disponível em: <http://www.math.ufl.edu/ vatter/teaching/calcnotes/ 4-4-green-curl.pdf>.

[40] HANSEN, C. D.; JOHNSON, C. R. Visualization Handbook. 1. ed. Academic Press, 2004. Hardcover. ISBN 012387582X. Disponivel em: <http: //www.amazon.com/gp/product/012387582x>.

[41] THEISEL, H.; RAUSCHENBACH, U. Curvis-visualizing the curvature of vector fields on the internet. Rostocker Informatik-Berichte, v. 23, p. 105$114,1999$. 
[42] HAN, J.; KAMBER, M. Data mining: concepts and techniques. San Francisco, CA, USA: Morgan Kaufmann Publishers Inc., 2000. ISBN 1-55860489-8.

[43] MOORE, D.; MCCABE, G.; CRAIG, B. Introduction to the Practice of Statistics. W.H. Freeman, 2009. ISBN 9781429216234 . Disponivel em: <http: //books.google.com.br/books?id=x0kkSwAACAAJ>.

[44] BEYER, K.; GOLDSTEIN, J.; RAMAKRISHNAN, R.; SHAFT, U. When is "nearest neighbor" meaningful? Database Theory-ICDT"99, Springer, p. 217-235, 1999.

[45] WALTER, J. A.; RITTER, H. On interactive visualization of highdimensional data using the hyperbolic plane. In: Proceedings of the eighth ACM SIGKDD international conference on Knowledge discovery and data mining. New York, NY, USA: ACM, 2002. (KDD '02), p. 123-132. ISBN 158113-567-X. Disponível em: <http://doi.acm.org/10.1145/775047. $775065>$.

[46] JOLLIFFE, I. Principal Component Analysis. Springer, 2002. (Springer Series in Statistics). ISBN 9780387954424. Disponível em: <http://books . google.com.br/books?id=_olByCrhjwIC $>$.

[47] JOIA, P.; PAUlOVICH, F. V.; COIMBRA, D.; CUMINATO, J. A.; NONATO, L. G. Local Affine Multidimensional Projection. IEEE transactions on visualization and computer graphics, v. 17, n. 12, p. 2563-71, dezembro 2011. ISSN 1941-0506. Disponivel em: <http://www.ncbi.nlm.nih.gov/ pubmed/22034378>.

[48] JR, J. H. W. Hierarchical grouping to optimize an objective function. Journal of the American statistical association, Taylor \& Francis, v. 58, n. 301, p. 236-244, 1963.

[49] JR, J. H. W.; HOOK, M. E. Application of an hierarchial grouping procedure to a problem of grouping profiles. Educational and Psychological Measurement, Sage Publications, 1963.

[50] JAIN, A. K.; DUBES, R. C. Algorithms for clustering data. Upper Saddle River, NJ, USA: Prentice-Hall, Inc., 1988. ISBN 0-13-022278-X.

[51] RASMUSSEN, E. Clustering algorithms. Information Retrieval: data structures and algorithms, p. 419-442, 1992. 
[52] GARCIA, D. Robust smoothing of gridded data in one and higher dimensions with missing values. Computational Statistics \& Data Analysis, v. 54, n. 4, p. 1167 - 1178, 2010. ISSN 0167-9473. Disponivel em: <http://www . sciencedirect.com/science/article/pii/s0167947309003491>.

[53] MATLAB. version 7.12.0 (R2011). Natick, Massachusetts: The MathWorks Inc., 2011.

[54] POPINET, S. Free computational fluid dynamics. ClusterWorld, v. 2, n. 6, 2004. Disponivel em: <http://gfs.sf.net/>.

[55] ADRIAN, R.; MEINHART, C.; TOMKINS, C. Vortex organization in the outer region of the turbulent boundary layer. Journal of Fluid Mechanics, Cambridge Univ Press, v. 422, n. 1, p. 1-54, 2000.

[56] STROUSTRUP, B. The C++ Programming Language. 3rd. ed. Boston, MA, USA: Addison-Wesley Longman Publishing Co., Inc., 2000. ISBN 0201700735. 